\title{
What's That Object? Learning Astronomical Concepts Through The Use Of The Aladin Program And Manipulation Of Astronomical Images
}

\author{
Melina S. de Lima, SENAI/CIMATEC University Centre, Brazil \\ Eduardo B. de Amôres, Feira de Santana State University, Brazil \\ José Vicente C. Santos, Bahia State University and SENAI/CIMATEC University Centre, Brazil \\ Vera A. F. Martin, Feira de Santana State University, Brazil
}

\begin{abstract}
Various studies have noted current shortcomings in the teaching and learning of science in schools, and the results of large-scale tests show that despite heavy investment in education, Brazilians' understanding of science test scores typically fall short of what could be if students had a consistent, high-quality basic education. This article summarizes the teaching plan and systematic study results for an activity titled "What's That Object?" implemented in the city of Salvador, Bahia state, Brazil, in 2015. Astronomical concepts were taught, and the Aladin software was used in the lessons, which included two computerized memory games produced for this activity. We believe that the results lend strong support to the notion that astronomy education can be improved and motivates educators to teach astronomical concepts at the elementary school level.
\end{abstract}

Keywords: Astronomy Education Research; Aladin; Astronomy Pedagogy; Educational Games

\section{INTRODUCTION}

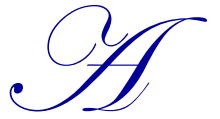

ccording to Lacanallo (2011), careful advanced planning of targeted lessons to promote learning is essential to improve science education, particularly considering the recent disappointing results of large-scale assessments that gauge elementary-level student performance on the national level in Brazil (Basic Assessment System, of Portuguese Sistema de Avaliação Básica- SAEB) and the international level (Programme for International Student Assessment, of Portuguese Programa Internacional de Avaliação de Alunos PISA). The results from both of these assessments are highly disappointing with regard to national hopes and goals for improved student learning at this level of education.

In Brazil, since the structural reforms proposed in 1996, in the first government of President Fernando Henrique Cardoso, several areas underwent deep reforms that unfold in the country until the present day, for example education, where a new training law was implemented, law 9394 of December 20, 1996, which advocates the implementation of national curricular guidelines and national curricular parameters, which, in the areas of science, to cite, advocate the use of tools that complement and aid the teaching and learning process.

Currently the country has evaluations focused on Basic Education whose results generate data about the current Brazilian educational system. These data are taken as basis for the Anísio Teixeira National Institute of Studies and Educational Researches,- of Portuguese Instituto Nacional de Estudos e Pesquisas Educacionais Anísio Teixeira (INEP) - Institution linked to the Ministry of Education, of Portuguese Ministério da Educação (MEC) - assist in the formulation and implementation of public educational policies. (Brasil, 1997). Examples of these evaluations are National High School Examination, of Portuguese Exame Nacional do Ensino Médio (ENEM), Evaluation of Children's Literacy, of Portuguese Provinha Brazil, National System of the Evaluation of Basic Education, of Copyright by author(s); $\underline{\text { CC-BY }}$ 
Portuguese Sistema Nacional de Avaliação da Educação Básica (SAEB) and the International Students Assessment Program, of Portguese Programa Internacional de Avaliação de Alunos (PISA)

Below are two graphs: the first compares the performance of Brazil with the Ibero-American countries that participated in all editions of PISA, the second makes a comparison with selected countries whose indexes emerge as the highest. Using a proficiency scale between 0 and 6, Brazil is on level 1 (between 335 and 409.5 points).

Graph 1. Comparison between Brazil and other Latin American countries (Portugal, Spain and Mexico) in all editions of PISA in the Science test. Source: Inep, 2011.

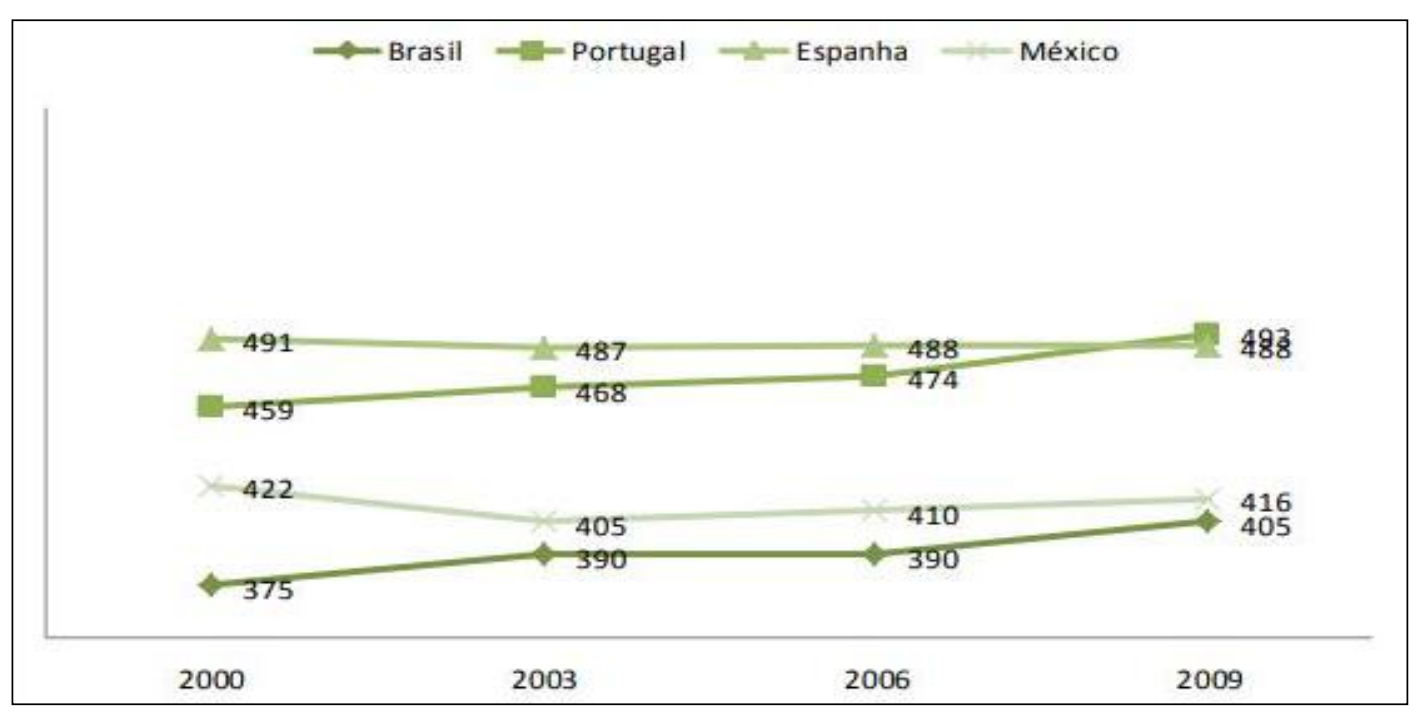

Graph 2. Brazil compared to countries whose indexes emerge as the highest (Japan, United States and Finland) in the science test. Source: Inep, 2011.

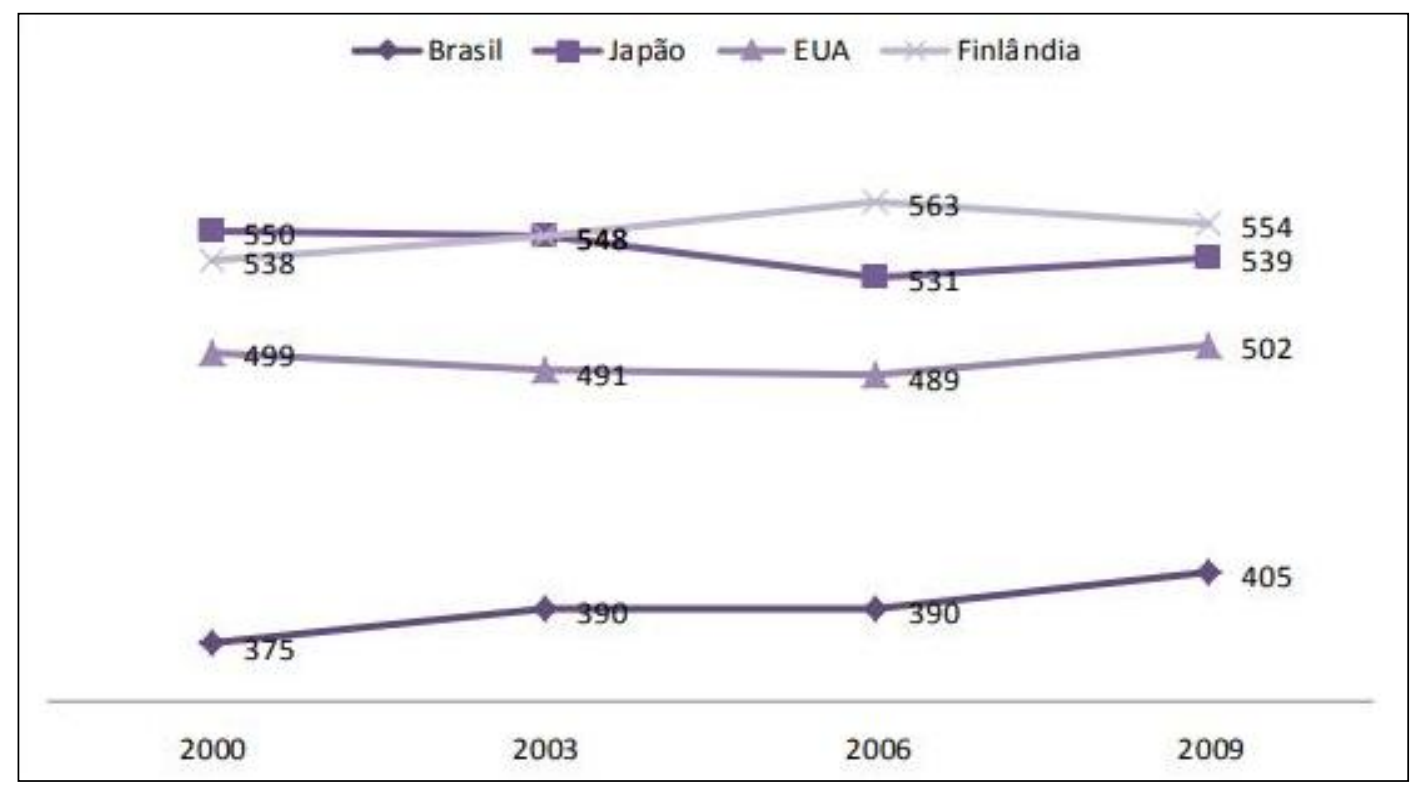


Corroborating the results, several studies point to a deficit in the teaching and learning of science in schools (Langhi \& Nardi, 2007) so that the National Curricular Parameters, of Portguese Parâmetros Curriculares Nacionais (PCN) suggests the teaching of concepts related to Astronomy since elementary school, given the importance of these be worked from the earliest moments of the child in the school stage, which makes necessary any initiative that encourages its approach in the classroom.

In this way, it is important for other researchers to know this reality, since in Brazil there is a deficit in the relationship of teaching and learning of science in schools, besides the fact that, in this research, it is demonstrated the effectiveness in the use of these types of experiment, in the process of teaching and learning, which, in itself, justifies the importance of work, minimally as a further mitigation bias of educational problems in the area.

Brazil's National Curriculum Standards (NCS) recommend teaching concepts related to astronomy beginning in elementary school, given the importance of exposing students to these concepts starting in the early years of education. This shows the need for any and all initiatives that support addressing astronomy in the classroom. According to this document:

The sciences have in common a search to understand nature, create representations of the world - how the universe, space, time, matter, human beings, and life are understood - discover and explain new natural phenomena, and organize and synthesize knowledge in theories that are developed and debated by the scientific community, which also works to disseminate the resulting knowledge to society. The history of science is marked by changes in the understanding of various natural phenomena, particularly since the sixteenth century, when the foundations of modern science were laid. This process began in astronomy, through the work of Copernicus, Kepler, and Galileo (in the sixteenth and seventeenth centuries), who, once they had more accurate data obtained using improved techniques, reinterpreted celestial observations and proposed the heliocentric model, which definitively displaced the Earth from the center of the universe. (Brazil, 1997, p. 33).

This part of the article proposes an activity that is in line with the NCS and its guidelines for the teaching of astronomy, using the Aladin software to teach these concepts. We describe the development and implementation of an activity titled "What's That Object?" performed with elementary students at a school in Salvador, Bahia state. A total of 16 students between the ages of 11 and 14 of both genders participated in this project.

The concepts covered in this activity focused on the manipulation of images, the recognition and classification of several astronomical objects such as nebulae, binary stars, galaxies, and clusters, and the use of the Aladin software program and some of its more basic tools.

The goals of the activity were to allow the student to:

- Become familiar with the concept of images and how they are stored;

- Understand how astronomical images are captured (obtained);

- Manipulate images of celestial objects;

- Become familiar with some concepts regarding some celestial objects;

- Identify and classify various astronomical objects; and

- Learn that astronomical images are stored on computers located in a data center.

Moreover, the activity "What's That Object?" mixed learning with fun through two memory games produced specifically for this lesson. Finally, the students learned to manipulate the tools of Aladin and to visualize and archive data and astronomical images, in addition to the concepts studied during the course of the activity.

Several reference works were consulted regarding concepts and the preparation of the lesson, including Bell, Wintten and Fellows (2015); Busselle (1998); Filho and Saraiva (2014); Hetem (1996); Langhi and Nardi (2007). Lacanallo (2011) was consulted as a reference for developing the games. 


\section{METHOD}

This work focuses on the conduction of activities described here for the teaching of astronomy concepts to elementary school students. It is part of a larger survey, lasting fifteen months, whose main objective was to verify how the use of Aladin software could be used to teach/learn astronomy concepts. The research was applied with elementary students (children), high school students (adolescents), undergraduate students (young people) and elementary school teachers. Here are some aspects related to the first group.

For this activity, a methodology based on a review of the literature on the subject was applied along with an exploration of all experimental type, with the participation of a researcher (one of the authors of this work), a Mathematics Teacher of the 6th year of elementary school, besides the students. The teacher participated in all phases of construction, adaptation and application of the research, including discussions and adaptations according to the results of the meetings so that the activity was in line with not only the validator documents already mentioned, but mainly with the average ages and the profile of the students.

The presentation had a descriptive character, for the purpose of explaining and detailing the most important elements of the methodological approach applied in the classroom with the student participants.

The entire process, from the questions to the development of the lesson plan, including the production and implementation of the activities, was carefully planned with the participation of the teacher and the researchers to provide solid grounding for the cognitive development of the acquisition of concepts presented to the learners.

Initially, a pre-test was applied using the same questions that would be applied on the post-test. The purpose of the pre-test was to assess prior knowledge in the students' cognitive structure. After the pre-test was corrected and the results analyzed, the researcher presented the Aladin software to the students and taught a lesson on it.

An introductory lesson on celestial objects was taught by the researcher and attended by the teacher and students. The students were introduced to concepts of astronomy, focusing on the following astronomical objects: stars, open star clusters, globular star clusters, nebulae, and galaxies (spiral, elliptical, and irregular). Two astronomical glossaries ${ }^{1}$ were used to define each type of object.

The researcher explained what each object was and its main features, showing representative images of each, simplifying her language to fit the age and maturity of the students.

In addition to the whiteboard and marker, the researcher used a PowerPoint presentation with 30 slides about the concepts described above to support her presentation of the concepts. Figures 1 and 2 show examples of the slides used in this lesson.

The students then had an opportunity to use the Aladin program to obtain images of various astronomical objects by entering their addresses (names) from the catalogs (New General Catalogue and Messier Catalog) in the program. Using the PowerPoint presentation, the researcher explained that each object is located at a given coordinate (point in the sky) at a certain distance from us and has a specific name and that the program can often locate an object and load images of it by using the name alone. The students also learned to manipulate data and some tools of the Strasbourg Astronomical Data Center $\left(\mathrm{CDS}^{2}\right)$ and to classify relatively simple objects by type. The students were told that the images that they would use in the memory game were obtained by the researcher in a manner similar to that in which they had accessed images on Aladin.

It is worth noting that the proposal does not have an instrument of control, but it does not invalidate the brilliance of the results since they can be indicative even for innovative control proposals in order to measure the relative percentages of advances in the learning process. This experimentation also does not have a large sampling, which

${ }^{1} \mathrm{http} / / /$ www.if.ufrgs.br/ fatima/glossario.html e http://www.fisica.ufmg.br/ dsoares/aap/aap.html.

${ }^{2} \mathrm{http}: / /$ cdsportal.u-strasbg.fr/

Copyright by author(s); $\underline{\text { CC-BY }}$ 
also does not invalidate it, but can be used in further attempts to consolidate the same result, in efficiency and also in effectiveness. In this way, although there is no classical control or an expressive sample, the proposal, as will be seen in its conclusive aspects, is a strong indicator of success in the proposal and new incursions can be improved towards a better planning of the methodology.

Subsequently, a fun activity was performed using the memory games noted above. Finally, the post-test was administered, using the same questions that had been used on the pre-test, given that the scores on the pre-test were very low (as shown below, in the pre-test results); the researcher sought to assess whether student performance improved following the lesson.

The inclusion of astronomical concepts is suggested by the PCN and this was explained to the teacher of the discipline, who still did not know in the PCN the suggestion to work such concepts from elementary school. She realized the relevance of the approach and, as already mentioned, actively participated in all stages, giving suggestions as the construction of the activity was being elaborated by the researcher.

Figure 1. Slide 3 from the lesson that introduces the concept of visualizing images with the human eye - Translation: Bullet Point: Understanding a few concepts about images and how they're made. Sub-Heading: To make images of the stars we need telescopes, and to understand how telescopes work, we need to know how the human eye works and how computers make images) ${ }^{3}$.

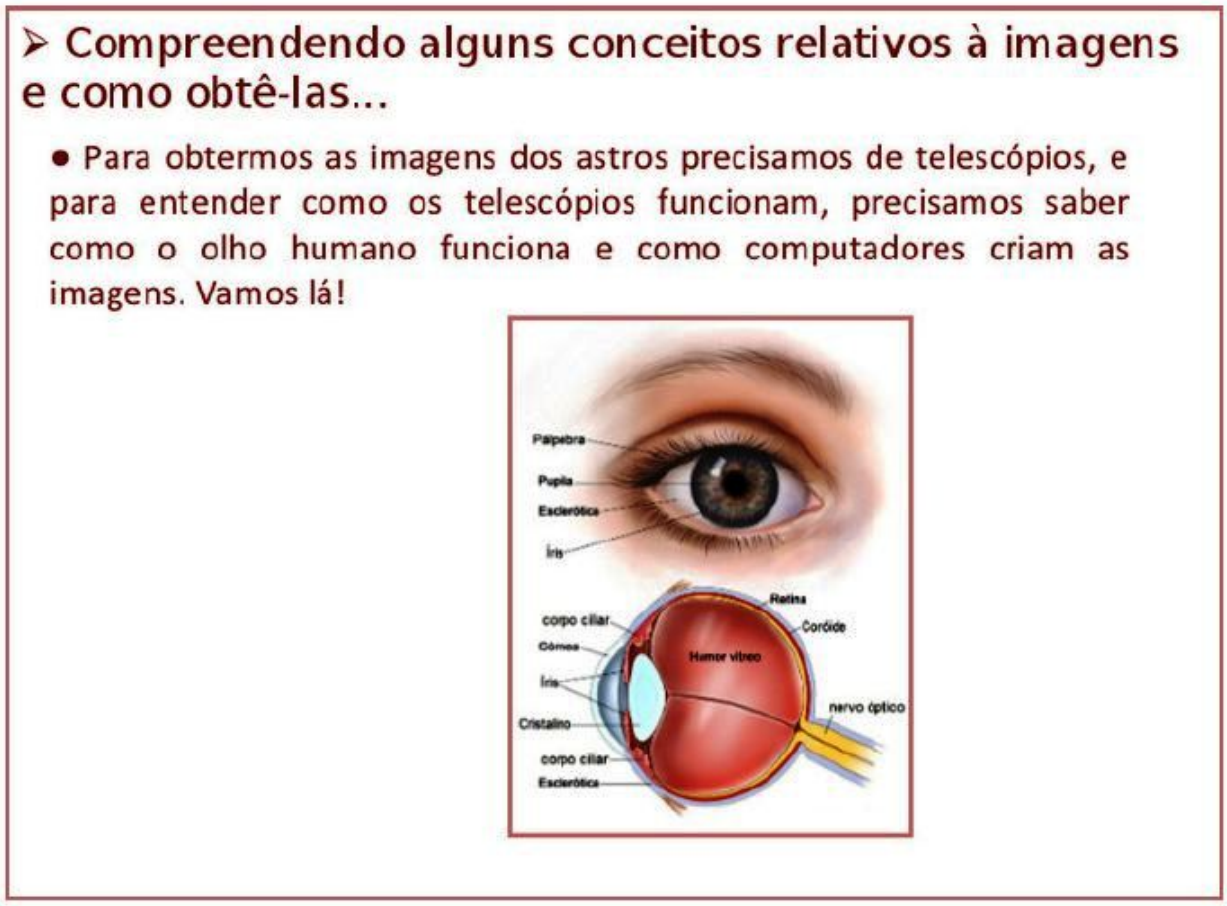

\footnotetext{
${ }^{3}$ Because it was a research done in Brazil, with Brazilian children, the content of the images is in Portuguese. However, in each figure was placed the translation into English.
} 
Figure 2. Slide 5 of the lesson on designating objects and searching for them in an astronomical database. (Heading: The celestial stars also have an address; Point 1: Celestial objects have addresses. To locate previously cataloged celestial bodies, their identifying "codes" are used. Point 2: Various catalogs of astronomical images exist. Aladin searches for an image in one of these catalogs. All it needs is the correct "code" and the image will appear. Point 3: Example: NGC6744: A beautiful spiral galaxy, much larger than our Milky Way. It is located 30 million light years away from us).

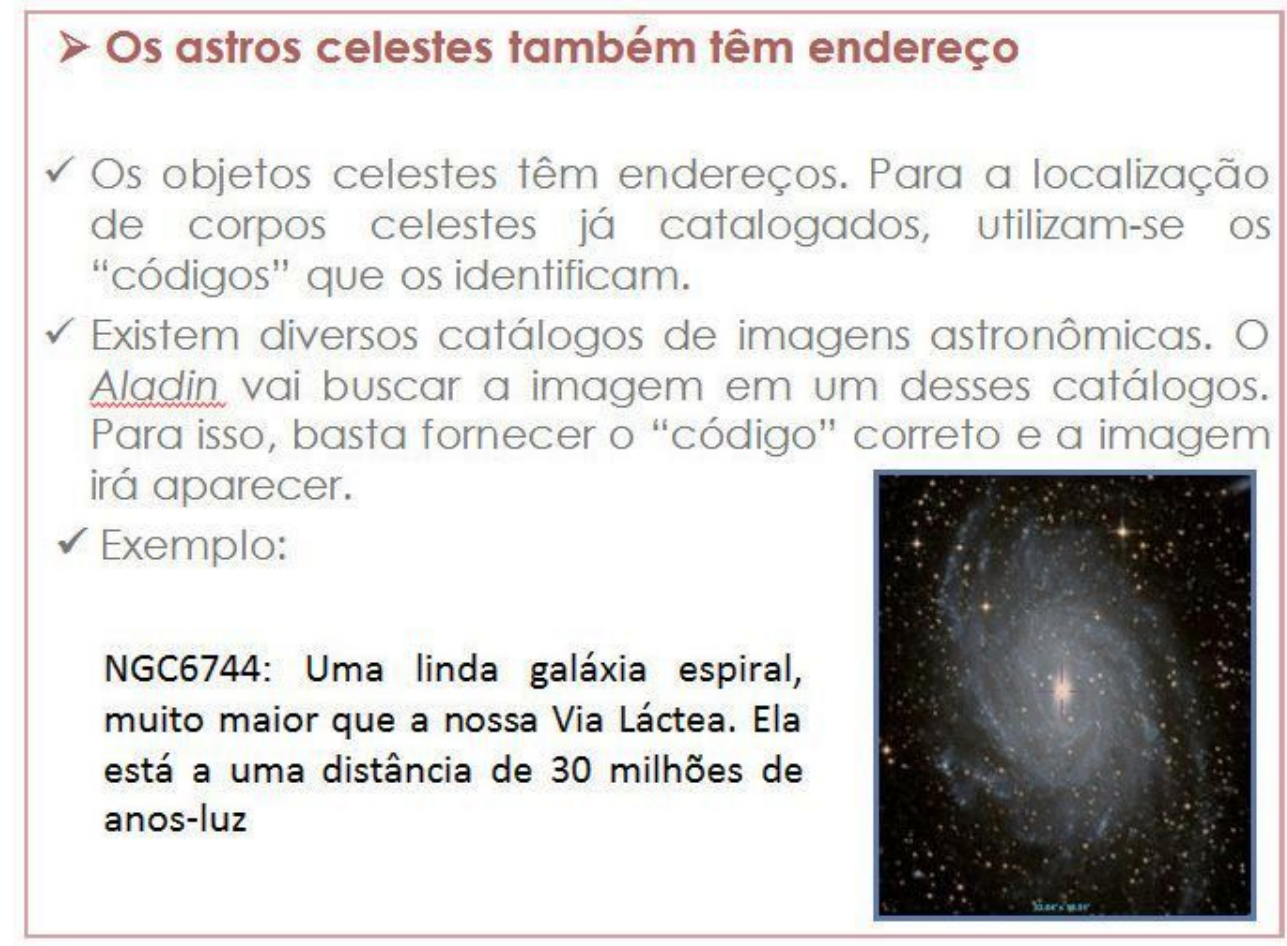

The inclusion of astronomical concepts is recommended by the NCS; this was explained to the subject teacher, who until then had not known about the NCS recommendation on incorporating these concepts starting in elementary school. She realized the relevance of the approach and, as noted above, actively participated in all of the stages, offering suggestions as the researcher was developing the activity. Five meetings were held between the two, totaling 10 hours.

Figure 3 summarizes the stages of the instructional methodology applied in this activity. It illustrates several important moments from each stage of the research project.

\section{Description of the In-Person Meetings}

This section describes the formal meetings of the activity, whether between the teacher and the class or between the researcher and the class. The formal meetings (Figure 3) are those in which the students participated. The first formal meeting with the students was conducted by the teacher, who informed the students of the importance and relevance of the activity planned. There was no need for the researcher to be present, given that this was simply an introductory lesson. The second formal meeting was used to apply the pre-test, which was performed by the class teacher, Ms. Alicia Silva.

The pre-test was corrected by the researcher with the aid of the teacher, and based on the scores, both considered it to be for the best for the students to take the same assessment for the post-test, after the explanatory lesson and the fun activity with the memory game. 
Figure 3. Schematic of the meetings with the students in activity 1

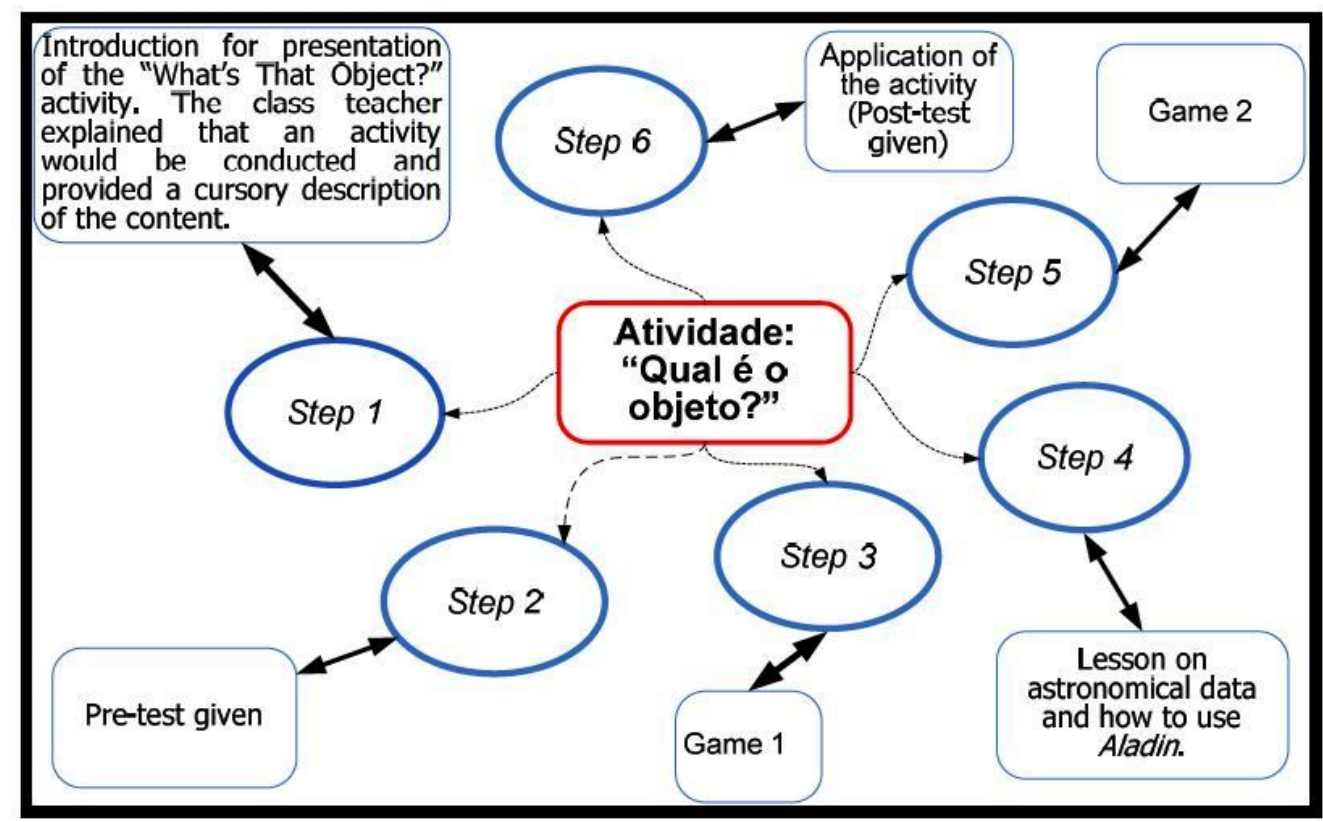

Figure 4. Summary of the lesson plan for the activity, "What's that Object?

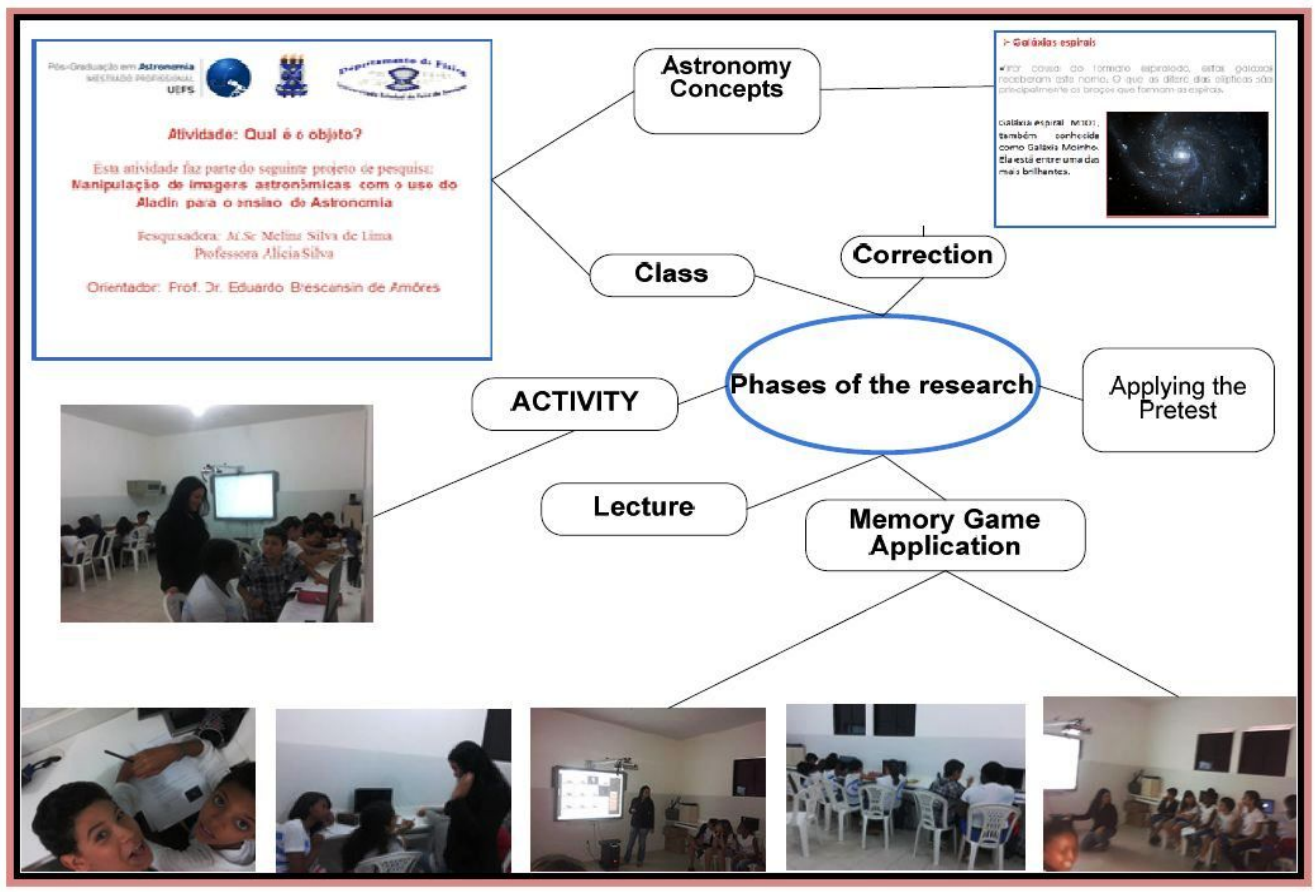


In the second formal meeting (the pre-test), the teacher reported that the students said they knew practically none of the concepts that it covered. On the post-test, however, student performance improved significantly.

The teacher reported to the researcher that the students were not enthusiastic about taking the pre-test. After the first class meeting, however, the students began to actively participate, ask questions, interact, and show interest. During the activity with the two memory games, the researcher's observations and audio and video recordings indicated even greater enthusiasm. The students appeared motivated and answered all of the questions (although some of their answers were incomplete, as discussed below).

The implementation of the activity (games and post-test, (that is, the last formal meeting) lasted approximately four hours and 20 minutes, occupying the entire morning. The students asked for additional time to continue playing the game, which they were excited about, given that it was a fun interlude, which is highly recommended for the age group of these students. The teacher and the researcher agreed because the game encouraged the learning of theory, anchoring the concepts and promoting the development of more complex subsumptions in their cognitive structures.

The teacher underwent training, although this is not the most appropriate terms, given the context. The researchers built all activity, from idea to completion, with the teacher's accompaniment. Therefore, the activities were designed to work concepts in the most appropriate way possible for the ages and school stage of the children. Meanwhile, as doubts arose in the process of conducting the teacher with the students, the researchers were guiding actions and responding to the doubts.

The activities implemented in the research were not restricted, therefore, only to the formal meetings of the researchers with the students, but, before that, in the procedural construction accompanied by the teacher and coordination of the school.

As they played, the students talked and discussed the celestial objects that appeared on the cards. They were divided into groups, and the groups were challenged to observe which would perform best. This encouraged healthy competition, as the students vied for the correct answers on the greatest possible number of combinations. The students competed both among themselves and with the computer, given that one of the games was designed so that it could be played either in groups or individually.

\section{Description of the Games}

Two games were developed. The first game was developed in the Java programming language. It contains five levels of difficulty, namely: very easy, easy, medium, difficult, and very difficult. Furthermore, for each level, the player could choose the number of cards to be played, as shown in Figure 5. In this same figure, we observe that the initial screen of the game asks for the player's choice of difficulty level. 
Figure 5. Home screen of the game (Jogo da Memoria Java = Memory Game Java; Escolha o Level = Choose a Level; Levels: Very Easy, Easy, Medium, Hard and Very Hard; Escolha Quantos Pares = Choose a Number of Pairs; Pares = Pairs; Avancar = Proceed)

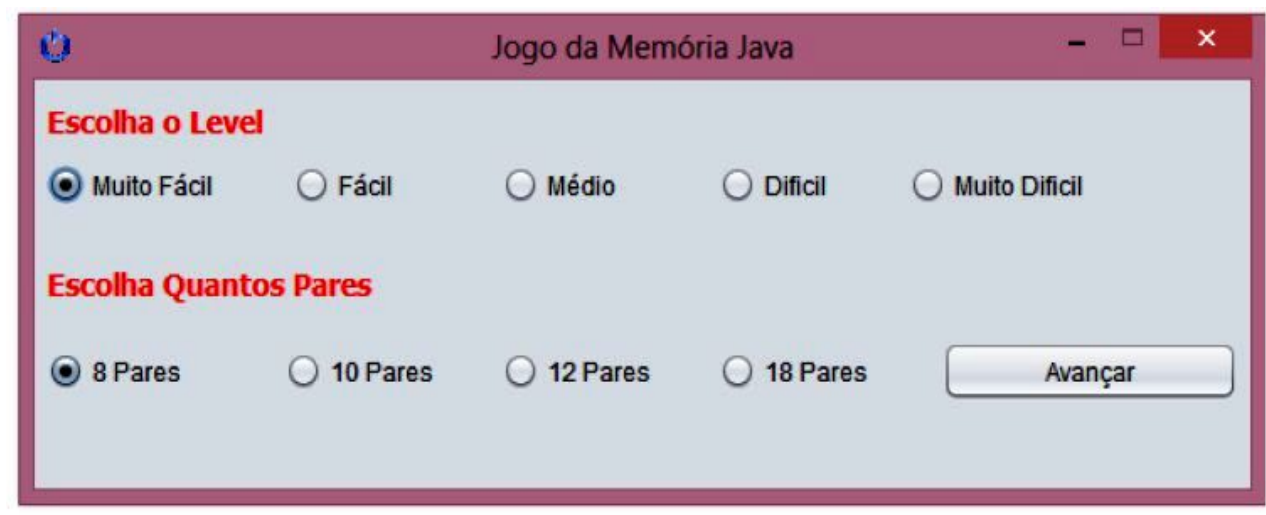

After the level is chosen, the cards appear initially "face up" (Figure 6) so that the player can memorize their locations. Next, the cards are turned "face down," and the player starts guessing.

The game closely resembles the traditional game of memory. Initially, the player is only called on to remember the positions of identical cards. The initial time to memorize the cards' positions and their random layout vary according to the difficulty level chosen.

Figure 6. Very difficult level using 12 pairs of cards

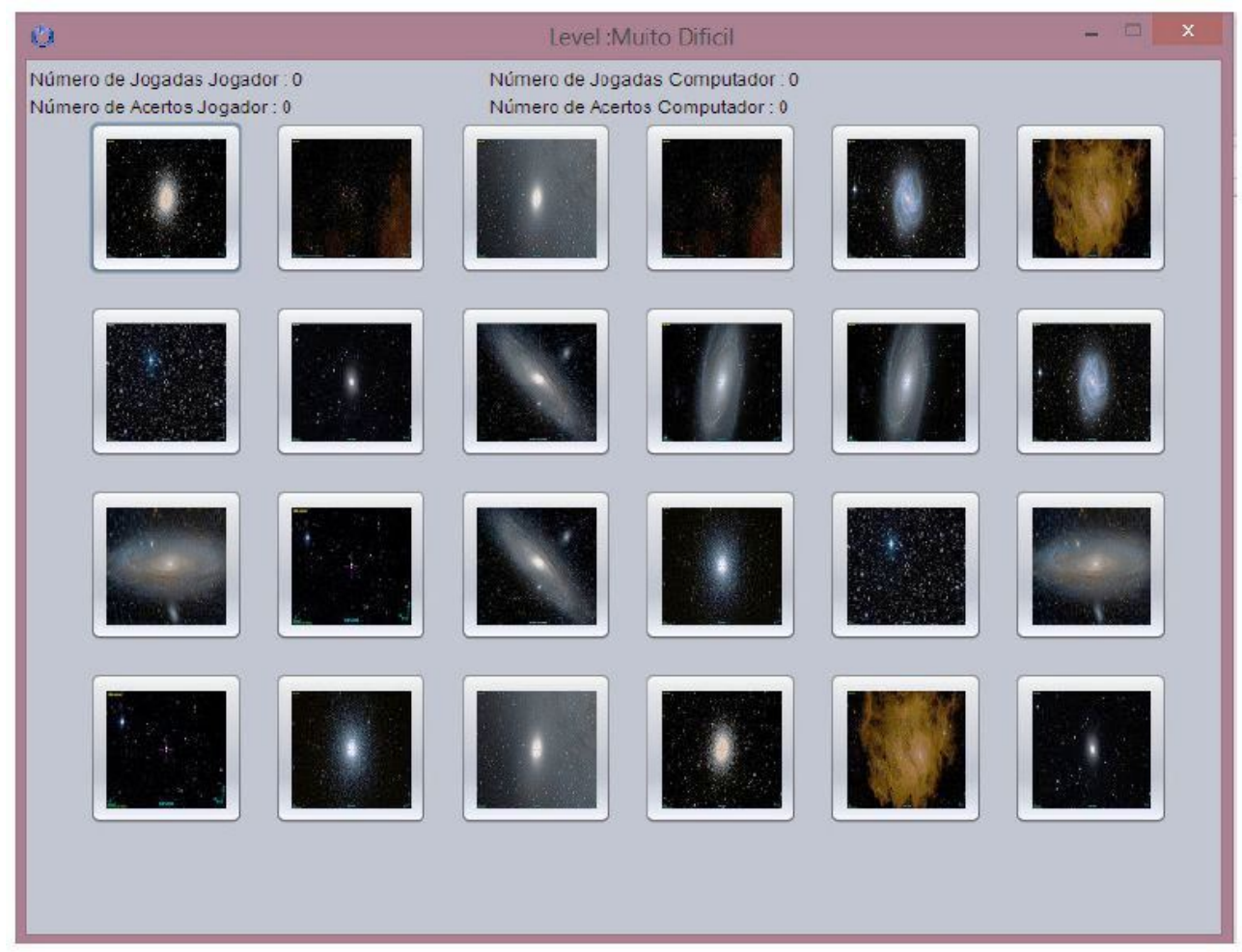


However, the game offers more opportunity for interventions by the teacher, as the students can be asked to name each object in addition to matching them (this was done by the researcher in the classroom experiment). The game trains the student's memory and, simultaneously, uses astronomical concepts through the teacher's interventions.

It is the responsibility of the teacher to introduce variations, creating circumstances that allow for the greatest possible diversity of teaching styles and thereby promoting learning about concepts related to astronomical objects. This game can also be used by high school teachers to teach physics concepts related to gravitation, movement, and the characteristics of stars, among other matters.

In this study, the first game served as an advance organizer (Uchoa, 2003), in that the researcher made comments about the astronomical objects as they appeared. The game served to introduce concepts in a playful dynamic, appropriate to the age level of the students. The game was played prior to the theoretical explanation of the lesson's content.

Figure 7. Computer playing while the player waits for his/her turn

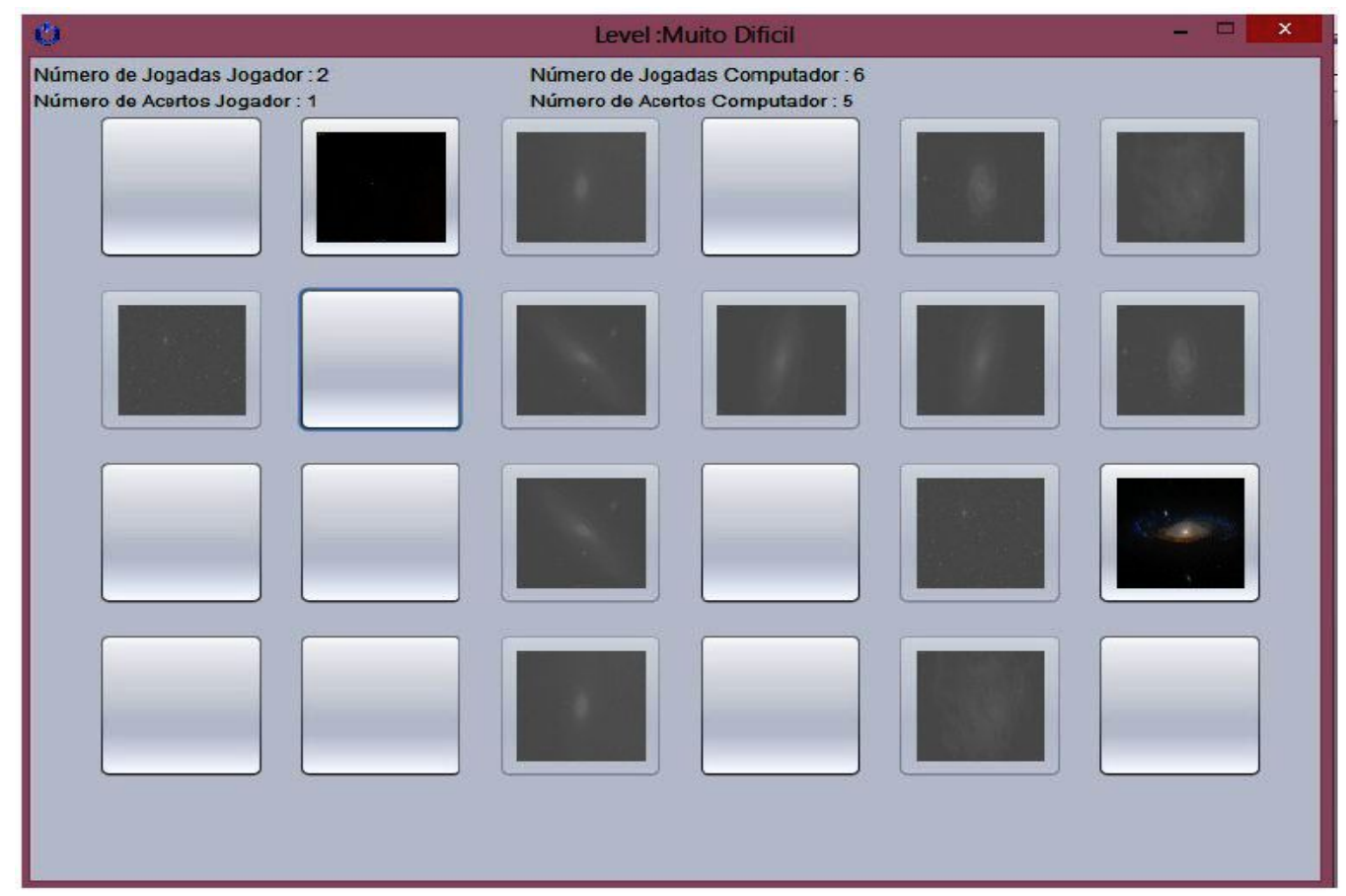


Figure 8. Researcher coordinating the moves of one of the groups

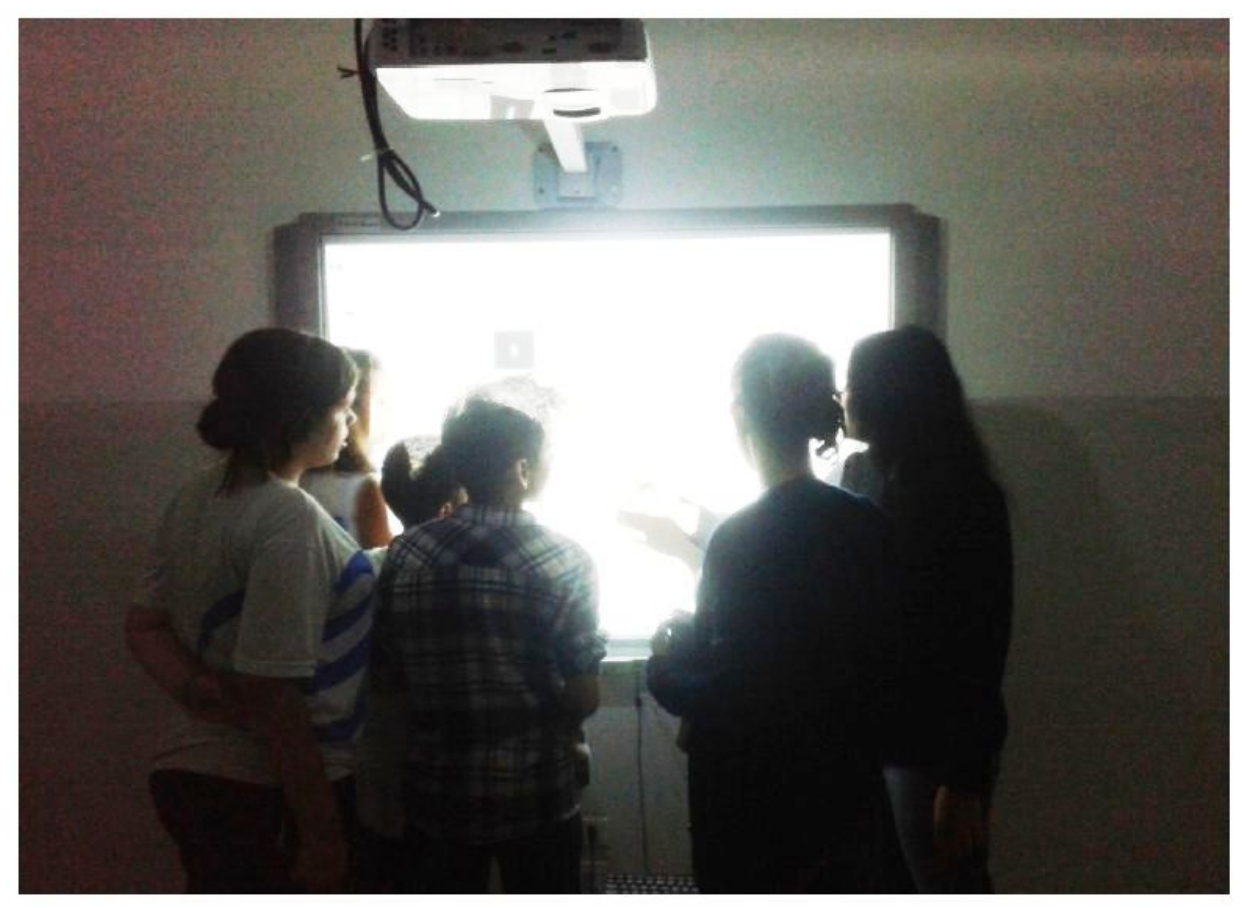

When the player misses, it is the computer's turn to play. He or she must wait for the next round to have another turn. Figure 7 shows an example of the screen when the computer is playing alone. At the end of the game, the player's and the computer's points are tallied to determine the winner.

The researcher and the teacher organized the groups, noting the points scored by each. At the conclusion of this stage of the game, the researcher announced the winner and took a break for lunch. Figure 8 shows the researcher presenting the instructions to the groups.

The students' enthusiasm prompted them to request that the researcher return with new games, and they reported having enjoyed the experience. One of the students remarked that the diversification of activities made the student happy to be in class.

As information about the stars arose, questions were asked by the students and answered by the researcher. Questions that strayed far from the activity's scope were redirected to topics more closely related to astronomical objects and information relevant to the study, given that the students showed great curiosity and wanted to know about many topics at once.

Game 2 was developed in JavaScript. Its screen displays 16 cards in a row, as shown in Figure 9. The right side displays the Start, Stop, Level, Time, Attempts, and Correct Answers buttons. The Start and Stop buttons are the only buttons students can directly access. The others display the running tally so that the player can monitor his or her performance. 
Figure 9. Layout of game 2

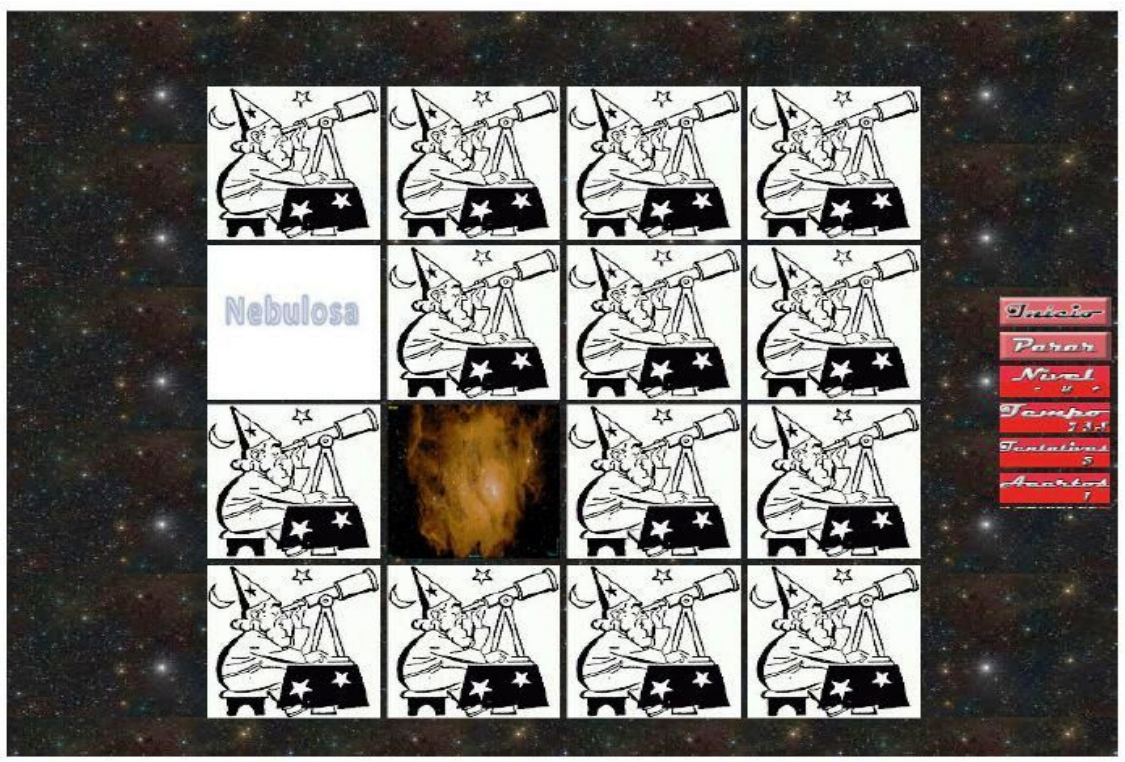

Initially, the cards appear "face down," as in a common game of memory. Next, the cards are all shown "face up" so that the player can memorize their respective positions. Next, after 10 seconds of preview, the letters are once again turned "face down," and the player can start the game. At the end of each round, the cards are "shuffled," that is, rearranged so that the player cannot, in effect, memorize their locations, which would spoil the game.

Figure 10. Cards "face up" for the preview (Buttons - translations: Spiral Galaxy; Globular Cluster; Elliptical Galaxy; Milky Way; Open Cluster; Binary Star; Our Galaxy; Nebula)

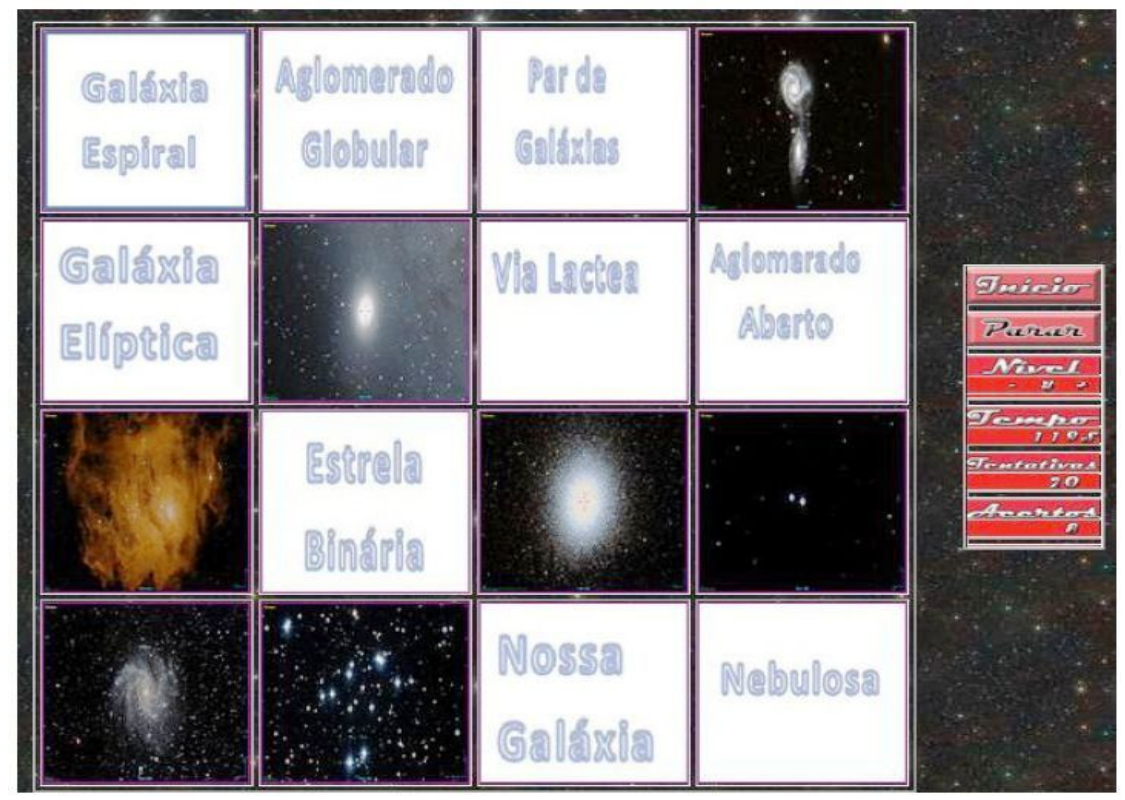


It is important to stress that, as shown in Figure 10, the student must match the card to the name of the astronomical object that it represents. When the match is not made correctly, the player yields to the next student, who will attempt to match the cards correctly; if the student is playing alone, then he or she can try again until the correct match is made. In that case, the player can attempt to improve his or her performance against the stopwatch on the right side. This game was performed after the theoretical lesson to determine whether the students were able to identify the astronomical objects and some of the concepts covered in the lesson.

The students had no difficulty matching the cards concerning the Milky Way, given that the researcher had already explained that no complete image of this galaxy exists because we are inside it, although it is possible to infer its shape from the distribution of a few tracers such as gas, dust, and stars. Figure 10 shows that the "Milky Way" card is the only card that has no image associated with it. After the completion of the game, a screen appears on the left, showing the score and registering the player's participation, as shown in Figures 11 and 12. The rules of the game were explained by the researcher before the students were divided into groups. The students asked questions to resolve their doubts, and then, the game began. Figure 13 shows the researcher explaining the rules of the game to the students.

Figure 11. Screen appearing at the completion of the game

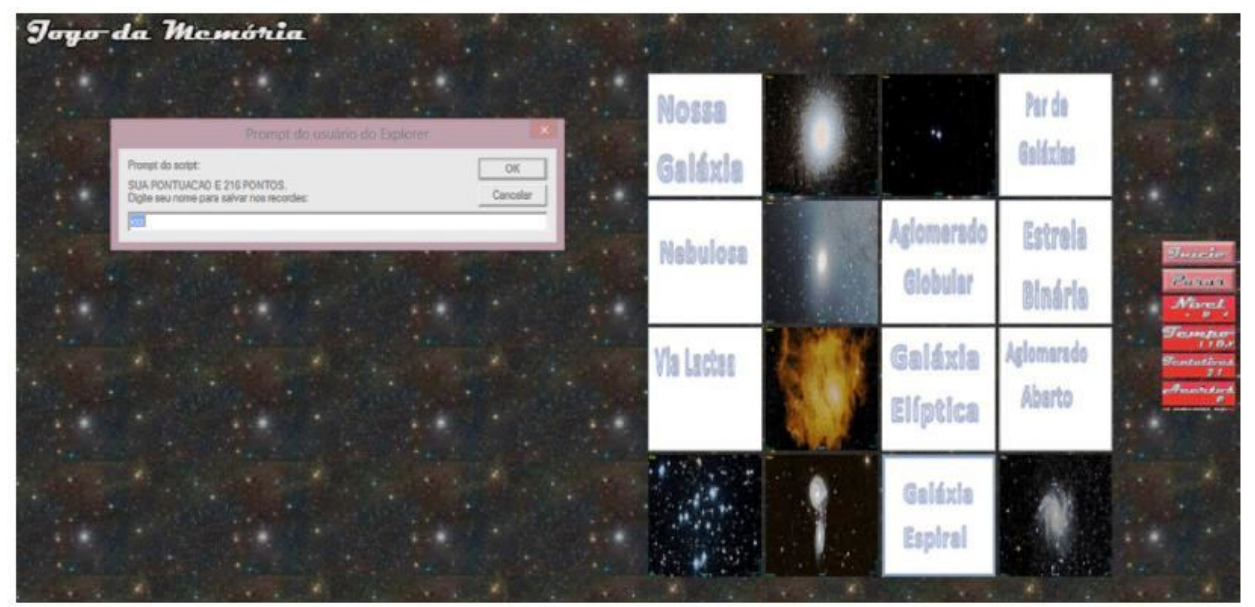

Figure 12. Screen showing the student's final score and requesting a name under which to record the results (Prompt do usuario $=$ Explorer user prompt; Prompt do script $=$ Script prompt; Sua pontuacao é $=$ Your score is 210 points; Digite seu nome para salvar nos recordes $=$ Enter your name to save it in our records; Cancelar $=$ Cancel)

\begin{tabular}{|l|c|}
\hline Prompt do usuário do Explorer & \\
\hline Prompt do script: & $\mathbf{X}$ \\
\hline SUA PONTUACAO E 210 PONTOS. & OK \\
Digite seu nome para salvar nos recordes: & Cancelar \\
\hline$\infty \alpha$ & \\
\hline
\end{tabular}


Figure 13. The researcher using the digital whiteboard to explain the rules of game 1

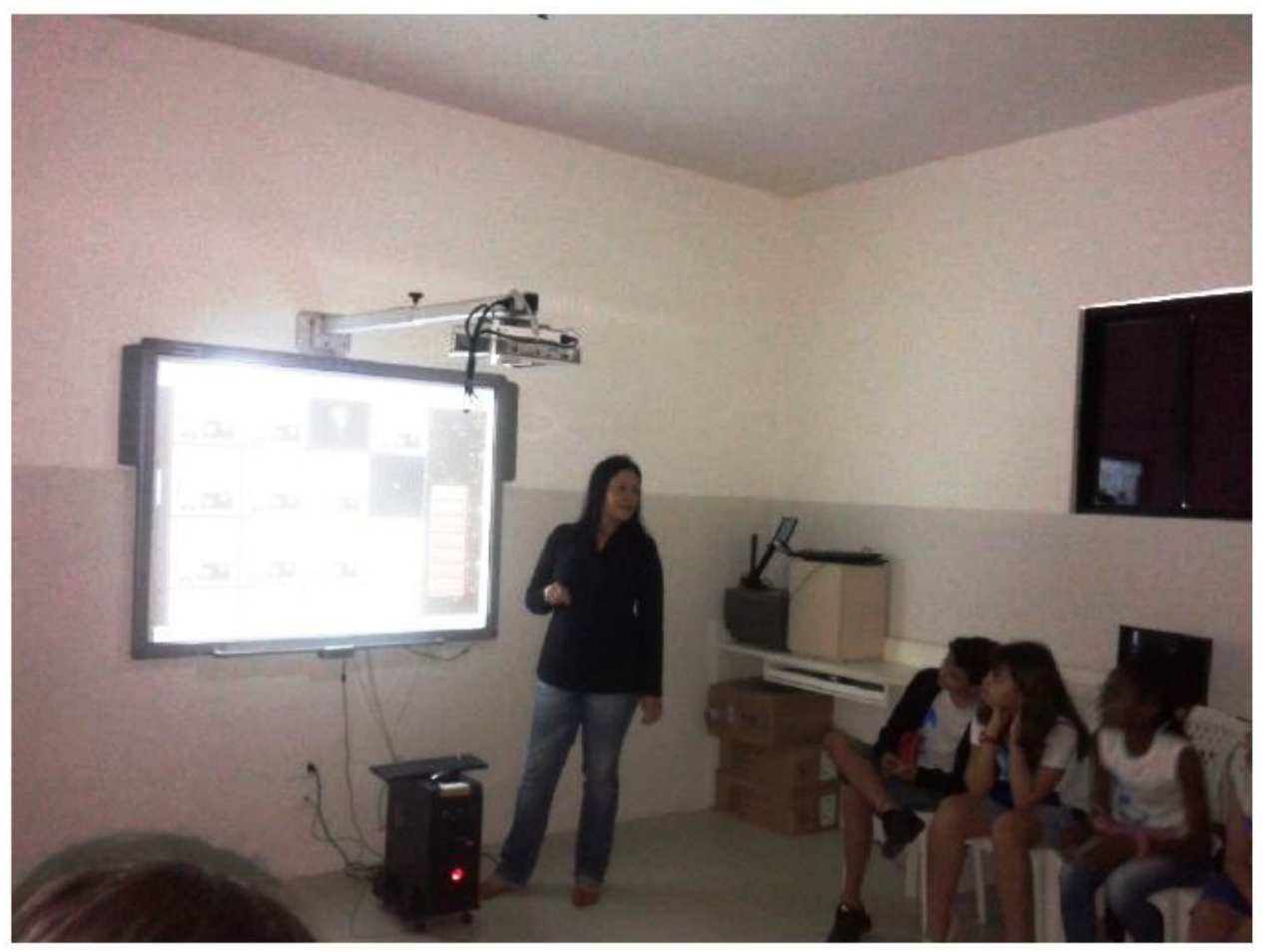

\section{Application Of The Post-Test}

The application of the post-test was the last stage of contact with the students who participated in the study. The post-test was corrected together with the teacher, having both a formative and a summative function. The formative assessment indicates the difficulties and progress arising from its development (Allal, Cardinet, \& Perrenoud, 1986). For this type of assessment, the strategies differ from one class to another.

Allal et al. (1986) states that formative activities are composed of three stages:

1) Collection of data about the students' conceptual difficulties;

2) Interpretation of the data obtained in the first stage for purposes of diagnosis and preparation for the third stage; and

3) Adaptation of the activities in light of the results of stage 2 .

Therefore, we consider the assessment to be formative, in that it involved the stages noted above. On the other hand, the assessment is also summative in that it sought to observe general and significant behaviors and to gauge the knowledge acquired, as recommended by Rabelo (2009).

\section{RESULTS AND DISCUSSION}

The pre-test and the post-test were identical, given that many answers were left blank by the students in the pre-test and due to the short time available for the implementation of the activity, which had to be accomplished during mathematics class for which the teacher was required to meet content standards. Another aspect to be considered is that the school did not allow additional time to be allocated for this study. 
Many other factors were analyzed, in addition to those noted here, and after concluding that this would not interfere in the process of meaningful learning, it was decided that the pre-test and the post-test would be identical.

This choice revealed that subsumptions previously non-existent in the students' cognitive structures were created, connected, and anchored; this conclusion was based on reviewing the audio and video recordings and the results of the post-test.

\section{Analysis and Interpretation of Pre-Test Answers}

The answers to the questions are described in Tables 1-6 with the respective graphs, followed by commentary. Subsequently, the questions and analysis of their results are presented through tables and graphs, in addition to the commentary associated with each.

Question 1 asked: "Answer with respect to the term 'astronomical object':"4, followed by the choices shown in Table 1. Only one student replied, "I know what it is " (Table 1); however, despite the student's confidence, the answer was wrong. Figure 14 shows that the student associated astronomical objects not with stars but with research tools such as telescopes. Among those who answered "I think I know what is," only one elaborated, but his answer was incorrect.

Table 1. Analysis of the pre-test answers to question 1: "Answer with respect to the term 'astronomical object"'

\begin{tabular}{l|c}
\hline \multicolumn{1}{|c|}{ Answers } & QUESTION 1 \\
\hline I don't know what it is & 8 \\
\hline I think I know what it is & 7 \\
\hline I know what it is & 1 \\
\hline Total & 16 \\
\hline
\end{tabular}

Graph 3. Percentage results for question 1 (Table 1); (Blue:Idon't know what it is; Red: I think I know what it is; Green: I know what it is).

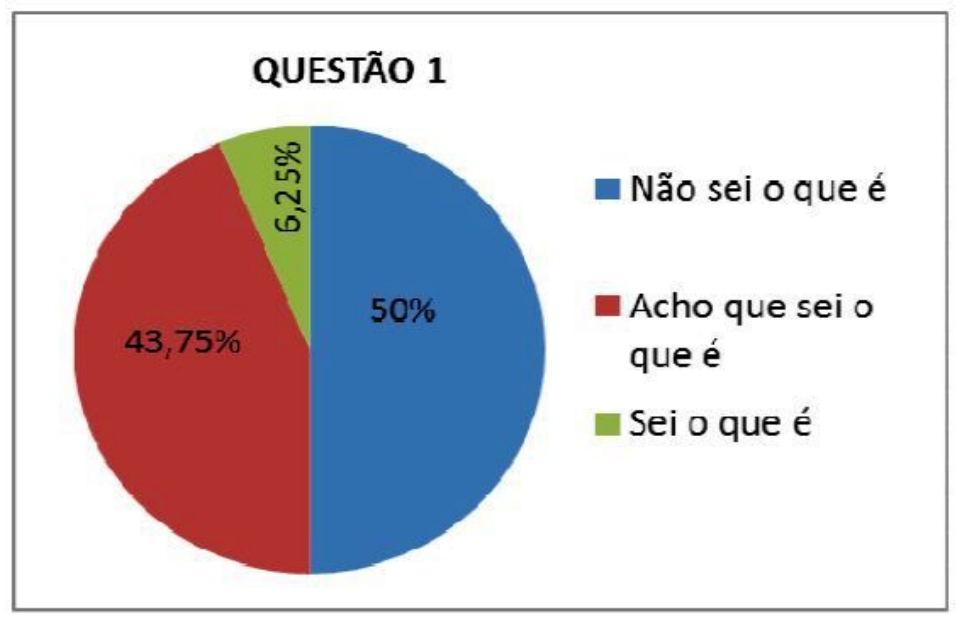

\footnotetext{
${ }^{4}$ During the lesson, the researcher told the students that an "astronomical object" refers to "celestial objects" rather than to items that common sense might suggest such as magnifying glasses or telescopes. Several synonyms and examples were used, such as stars, the Moon etc. 
Figure 14. Answer of the only student who marked choice $c$ in question 1 (Printed text: use translations from the previous figure and table; Handwritten text: Astronomical objects are objects that scientists use to do research on outer space).

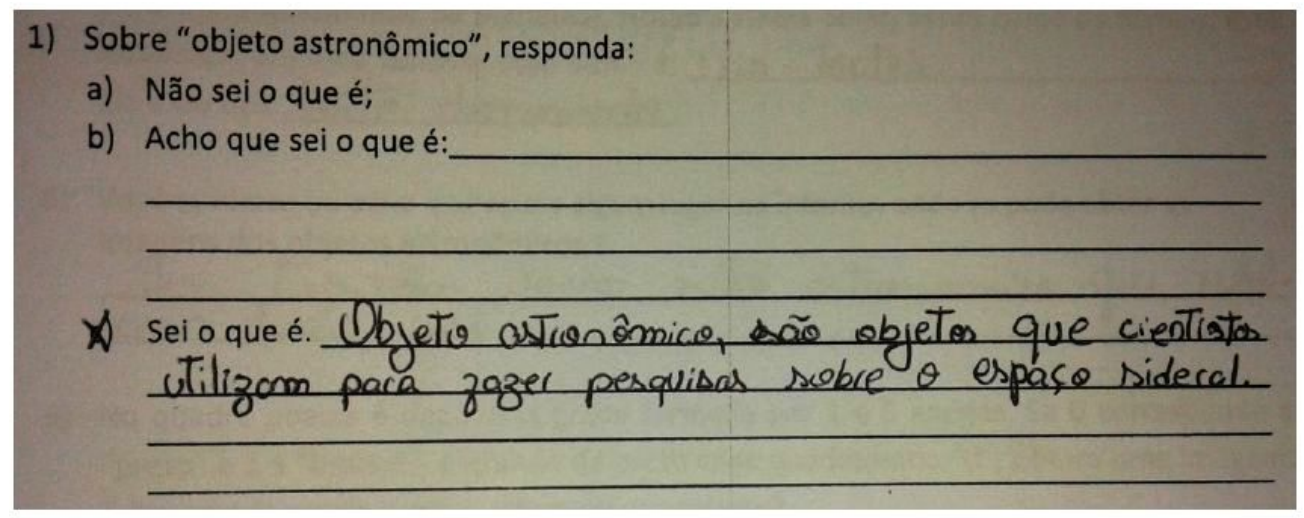

Question 2 was about the visualization of images, asking students to complete the sentence "Astronomical objects..." by choosing one of the options shown in Table 2, with the correct answer being letter a. Only $28.6 \%$ of the students answered correctly, as shown in Table and Graph 3. Analyses of these results quickly revealed that not even half of the students answered correctly and that two students left it blank. It is worth highlighting, however, that this is not a trivial or obvious response, given that the students, teachers, and the public in general typically associate "object" with something that human beings can use. However, because it was explained that these objects were stars of the cosmos, the universe, such as the moon, stars, and galaxies, among others, this result can be associated with a total absence of subsumptions in the students. When we mention "astronomical objects" without a proper prior explanation, it is relatively natural that most people do not think of stars, planets, or nebulae, for example, as "objects."

Table 2. Analysis of pre-test answers to question 2: "Astronomical objects... "

\begin{tabular}{l|c}
\hline \multicolumn{1}{|c|}{ Answer } & QUESTION 2 \\
\hline a) They have different colors; & 7 \\
\hline b) They have no colors & 4 \\
\hline c) They are "black and white" & 3 \\
\hline Left blank & 2 \\
\hline Total & 16 \\
\hline
\end{tabular}

Graph 4. Percentage results for question 2 (Table 2.) - Deixaram em branco $=$ Left blank

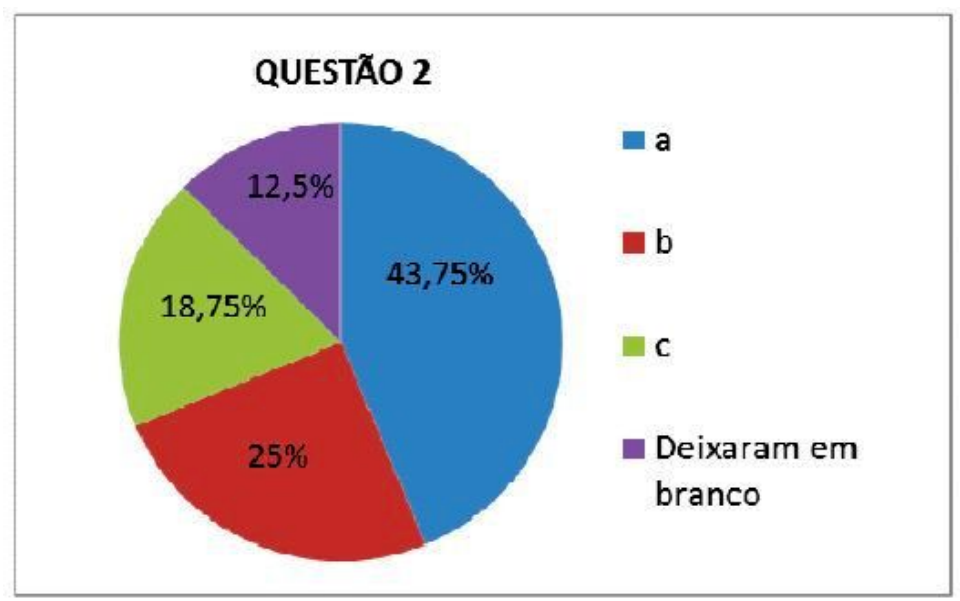


Question 3 asked the students to complete the phrase "All astronomical objects..." with the options described in Table 3. On this question, the results showed improvement, but it was still expected that everyone would know that celestial objects vary in size.

Table 3. Analysis of the correct pre-test answers to question 3: "All astronomical objects..."

\begin{tabular}{l|c}
\hline \multicolumn{1}{c|}{ Answer } & QUESTION 3 \\
\hline a) Are the same size & 1 \\
\hline b) Vary in size & 12 \\
\hline c) Are almost the same size, with little variation & 1 \\
\hline Left blank & 2 \\
\hline Total & 16 \\
\hline
\end{tabular}

Graph 5. Percentage results for question 3 (Table 3) - Deixaram em branco $=$ Left blanck

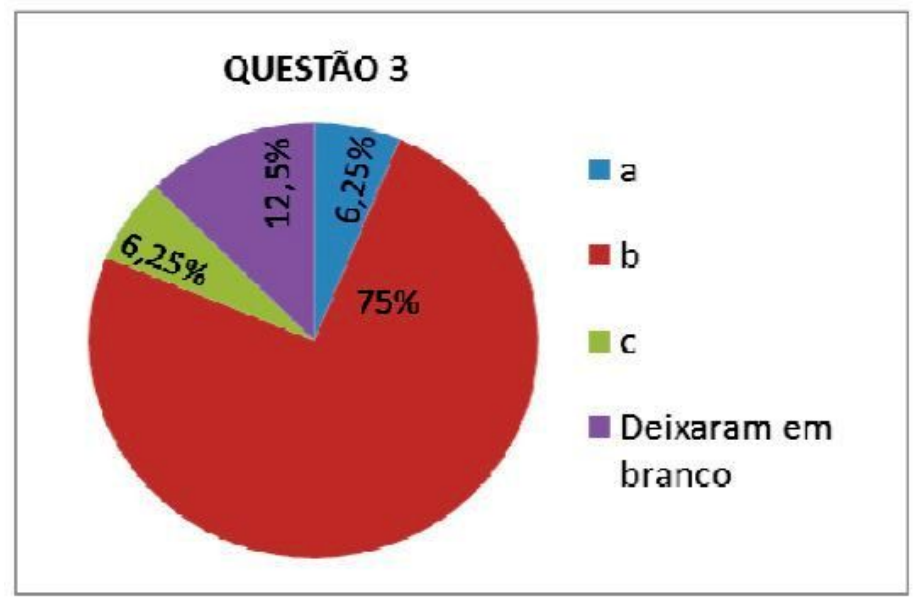

Question 4 asked the students to cite three types of celestial bodies (astronomical objects) that they knew or had "heard of." Of the 16 responses analyzed, only two were considered satisfactory. This result represents $12.5 \%$ of the students assessed. However, they may have been induced due to the explanation given by the researcher. Figure 15 shows a correct answer, whereas Figures 16 and 17 show two wrong answers.

Figure 15. One of the two correct answers (Printed text: Cite three types of celestial bodies (astronomical objects) that you know or have heard of. Handwritten text: Planets, satellites and stars).

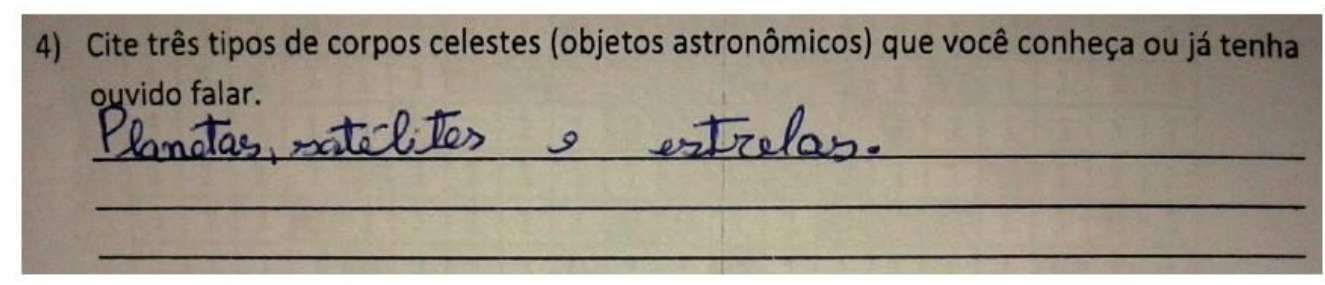

Half of the students reported that they were not aware of any. They gave answers such as "I don't know" and "I've never heard of any" or they left the space blank. This represents eight of the 16 students who answered the questionnaire about prior knowledge. In addition of the students who answered correctly, left the space blank, or stated that they did not know the answer, six students gave answers that were considered wrong. 
Figure 16. Example of one of the responses given by a student who claimed not to know any astronomical objects (50\% of the total) (Printed text: Cite three types of celestial bodies (astronomical objects) that you know or have heard of. Handwritten text: I've never heard of any and don't know).

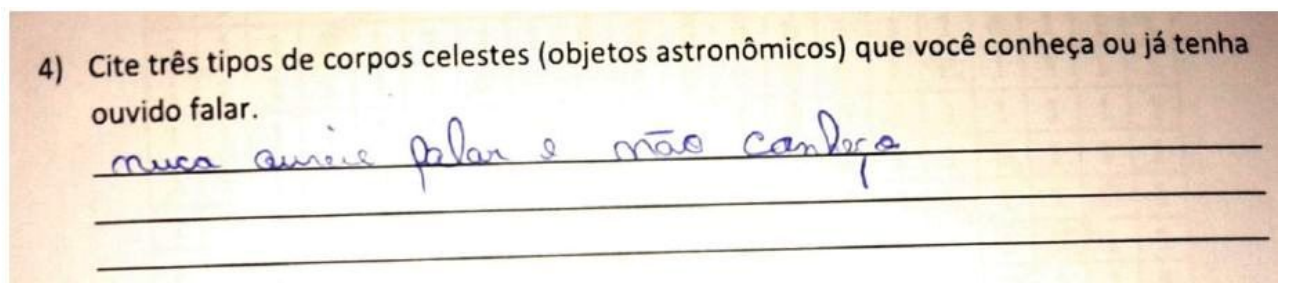

We should note here that the term employed in general usage could confuse students because it had more than one possible meaning; after much group discussion, it was decided to include this term among those contemplated by the item in question.

Figure 17. Answer considered unsatisfactory (Printed text: Cite three types of celestial bodies (astronomical objects) that you know or have heard of. Handwritten text: Shooting star, etc).

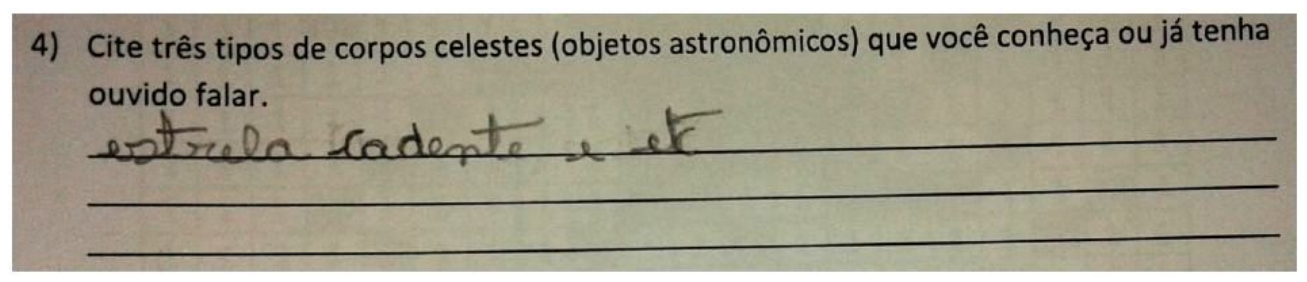

Question 5 presents the image of a galaxy and asks students to choose the correct term for the astronomical object represented (the choices included galaxy, planet, star, other, or "I don't know").

Of the 16 responses analyzed, six were correct; that is, six students chose letter $a$, the correct answer. This result means that not even half the students were able to identify the image as representing a galaxy. Twenty years ago, this result might have been considered less serious than today, when we live in the information age and so much information is available on the Internet through search engines. However, because the Internet is so vast, individuals need guidance and orientation to find relevant information about astronomical concepts. This discussion confirms the need to teach astronomical concepts in schools as a subject in itself.

It is worth emphasizing that the students assessed attend an upper-middle-class private school in the city of Salvador, meaning that most have a computer available at home, in addition to living in a state capital and attending a school with a computer lab and a digital whiteboard. It is very likely that if this pre-test were applied in a school in which the students do not have these resources available, the results would be worse.

For question 6 (shown at the top of Figure 18), only two answers were correct; that is, $12.5 \%$ of the students were able to describe any information about celestial objects. The other answers were incorrect or left blank. 
Figure 18. Example of the 50\% who said they did not know (Printed text: If you mentioned a type of astronomical object (celestial body, celestial object), write what you know about it. Handwritten text: Planet = Celestial bodies that orbit around a star).

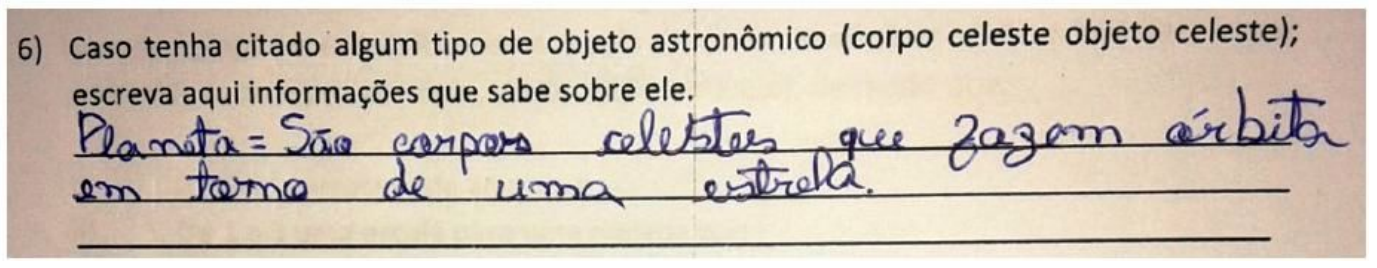

For question 7 (Figure 19), no student answered all of the questions correctly. Of the 16 students evaluated, four filled in the first blank with the correct answer; that is, only four students knew that the solar system has seven planets in addition to Earth. Although the fact that Pluto is no longer considered a planet after having been reclassified as a dwarf-planet, which received wide coverage by television and Internet media, the majority of students did not know this information. Moreover, some students even answered with another number, showing total ignorance about the solar system, which is covered in beginning science classes at the earliest grade levels.

This finding prompts us to wonder about the role of not only the teacher but also the policies and the agency governing education in our country that sets the content standards for each grade level. We will not delve into that discussion, given that it falls outside the scope of this study, but at least one observation about the process by which education is taught is necessary. At a time when access to the Internet and, therefore, to all types of information is widely available, how can we encourage our students to seek out and study topics that are important in a scholastic sense?

Figure 19. One student's answer to question 7 (Fill in the blanks: I live on planet Earth. It is in our Solar System, with [8] others (enter the number of planets). Our Solar System, as with the others, is located in a Galaxy, named the: [Milky Way]).

\section{7) Complete as lacunas: \\ Eu moro no planeta Terra. Ele está no nosso Sistema Solar, com mais _ \& (informe a quantidade de planetas). Nosso Sistema Solar, assim como os demais, está localizado em uma Galáxia cuio neméé- Via I ńétén}

The second blank (Figure 19) was correctly filled in by eight students, meaning that only $50 \%$ of the students knew that our galaxy is called the Milky Way. None of the students filled in the third blank correctly. Figure 19 shows one student's answer.

The answers to question 8 (label in Figure 20) ranged from Google to Wikipedia to Google Earth and Google images, in the case of this student. This scenario is most likely related to the searches the students perform in the course of their activities and to find images in general. Approximately $44 \%$ of the students did not answer the question. That is, seven of the 16 students left the space blank. No student cited a software program specifically pertaining to astronomical images.

Figure 20. A student's answer to question 8 (Do you know or think there exists a site on the Internet where images of astronomical objects can be found?) - (Yes, in Google Earth or in Google Images)

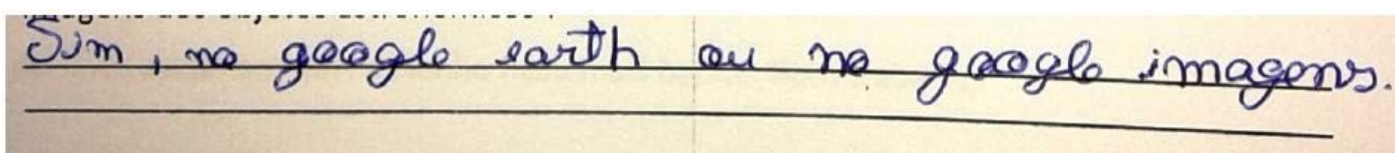


Question 9 showed the students a grid composed only of the numbers zero and one, informing the students that the numbers corresponded to the colors black and white, respectively, and that the students should fill in the squares ${ }^{5}$ with the number zero (see Figure 21). Although all students filled in the illustration as requested, only one of them associated the figure with a galaxy; even this student listed "galaxy" as only one of two possibilities: black hole/galaxy, as shown in Figure 21.

Six students answered that the figure represented a black hole, one student suggested two possibilities, another student replied that the drawing represented the sun, and the others left the space blank.

Figure 21. A student's answer to question 9, which directed the student to fill in the squares containing the number zero. (The square below contains a grid of only 1 and 0 . If 0 represents black and 1 represents white, filling every 0 grid cell with black will make an image. Does the resulting image look like any celestial object? [wormhole/galaxy]).

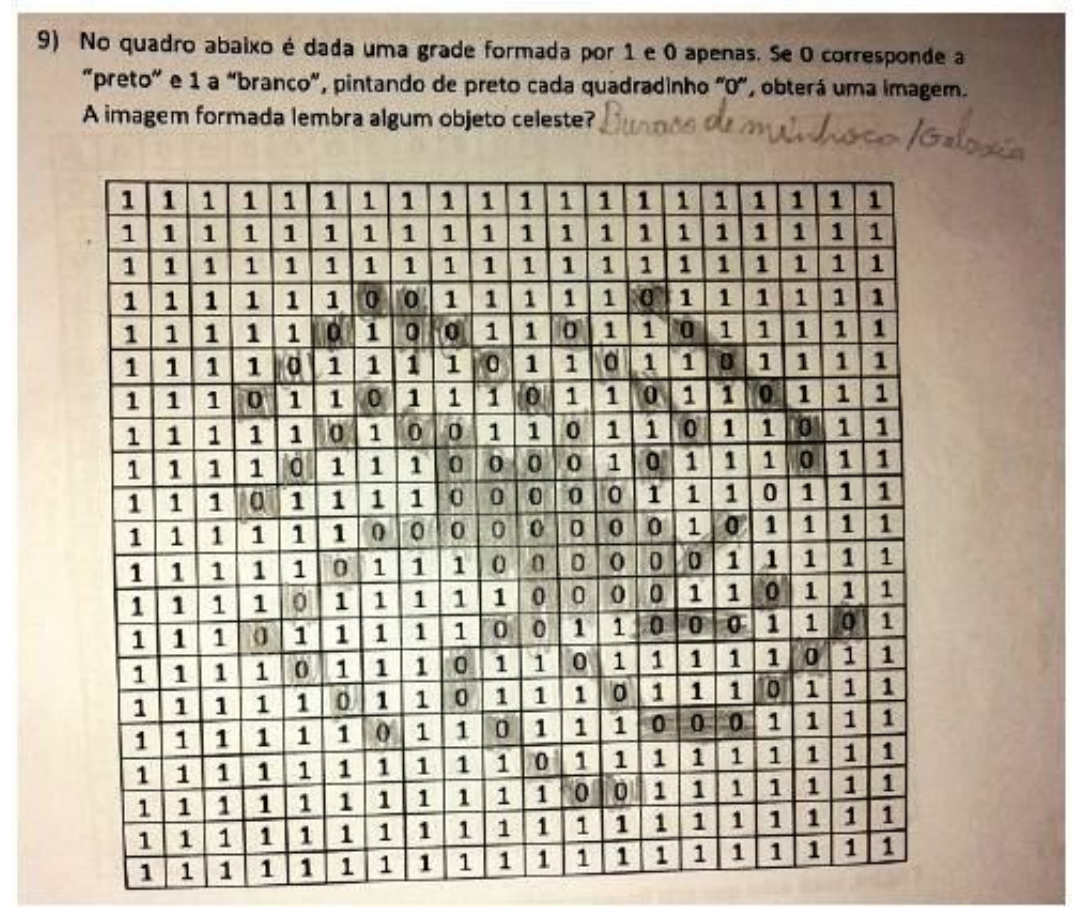

One should note that this is a rough representation of a galaxy, given that the arms of a spiral galaxy are not "bent" as shown in the figure. The reason is that the activity directed the students to fill in only the "zeros" and "ones" in the grid.

Question 10 presented the same grid but now with different numbers to simulate a charge-coupled device (CCD) image; the image that appears now is colored. This question had very similar results; the students gave the same answers found in question 9.

\section{Analysis of the Post-Test Results}

As reported and duly justified above, the post-test applied in the activity "What's That Object?" consisted of the same questions that had appeared previously on the pre-test. The main objective of the activity was to provide meaningful learning of concepts concerning astronomical objects to elementary-school students in the sixth grade.

${ }^{5} \mathrm{http}: / /$ www.slideshare.net/anapicao/brochura-numeros-1ano 
Next, we discuss and analyze the answers to the post-test following all of the steps performed with the participating students. The same 10 questions were scored, now at another stage of the activity, to detect meaningful learning by the students. The results are discussed one by one, considering their particular characteristics. Some answers were chosen to illustrate the comments.

In contrast to the results obtained on the pre-test, question 1 showed improvement, as shown in Graph 4 and Table 4. Whereas only one student had answered "I know what it is" on the pre-test, $50 \%$ of the students claimed to know the answer on the post-test, whereas only one admitted to not knowing.

Table 4. Analysis of post-test answers to question 1: "Answer with respect to the term 'astronomical object""

\begin{tabular}{l|c}
\hline \multicolumn{1}{|c|}{ Answer } & QUESTION 1 \\
\hline I don't know what it is & 1 \\
\hline I think I know what it is & 7 \\
\hline I know what it is & 8 \\
\hline Total By Level & 16 \\
\hline
\end{tabular}

Graph 6. Percentage results for question 2 (question and options in Table 4)

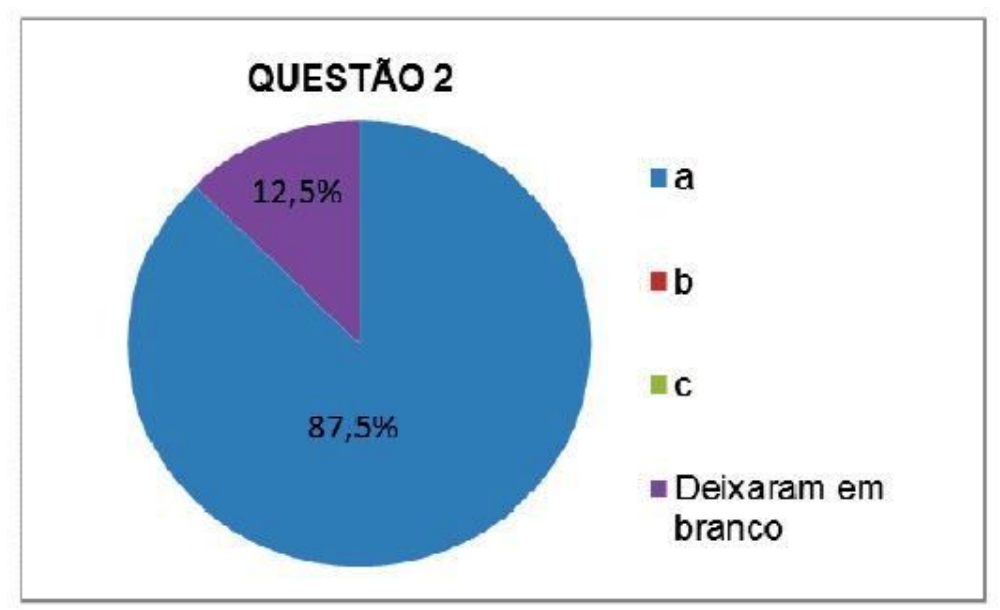

However, it is not sufficient to simply count the number of students who claimed to know the answer; we care about the quality of the answers. Using descriptive analysis of what followed the choice of option, we found that only one of the students who claimed to know the answer failed to answer satisfactorily. Among those who claimed to know, two did not answer satisfactorily. Thus, there were a total of four incorrect and 12 correct answers, which represents a significant improvement and shows that concepts previously unknown to the students now seem to be formed in their cognitive structures. Figures 22 and 23 show two responses to the first question that were analyzed. 
Figure 22. A student's response to question 1 (Printed text: Provided above: I don't know what it is; Handwritten text: A celestial body formed by everything that is of nature, like a comet).

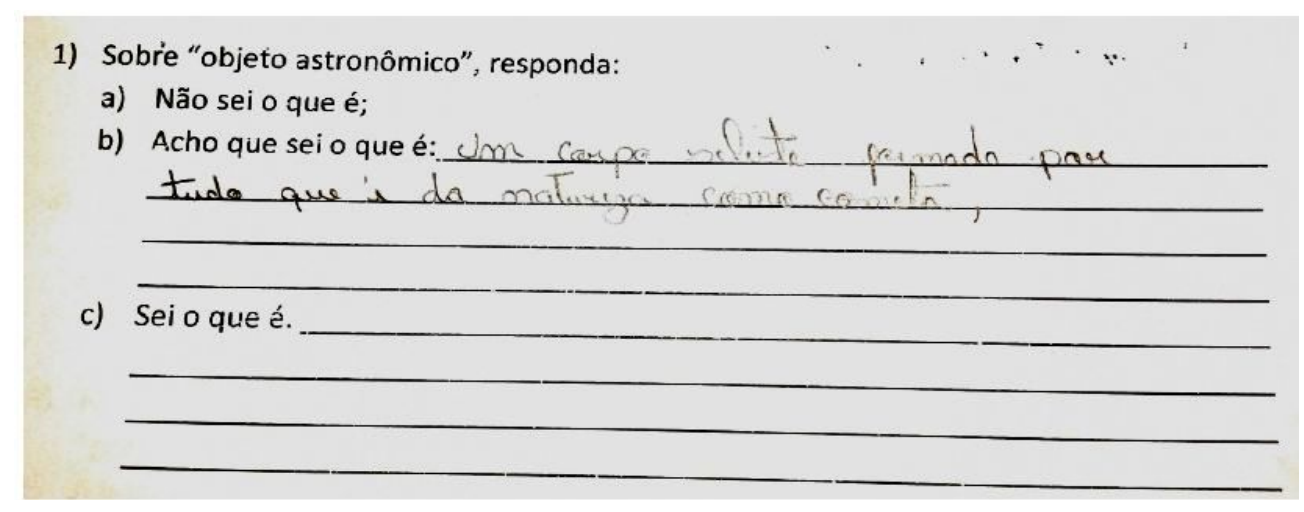

Figure 23. A student's correct answer to question 1 (Printed text: Provided above Handwritten text: It is the same as a celestial body, such as planets, galaxies, nebulas, stars, etc).

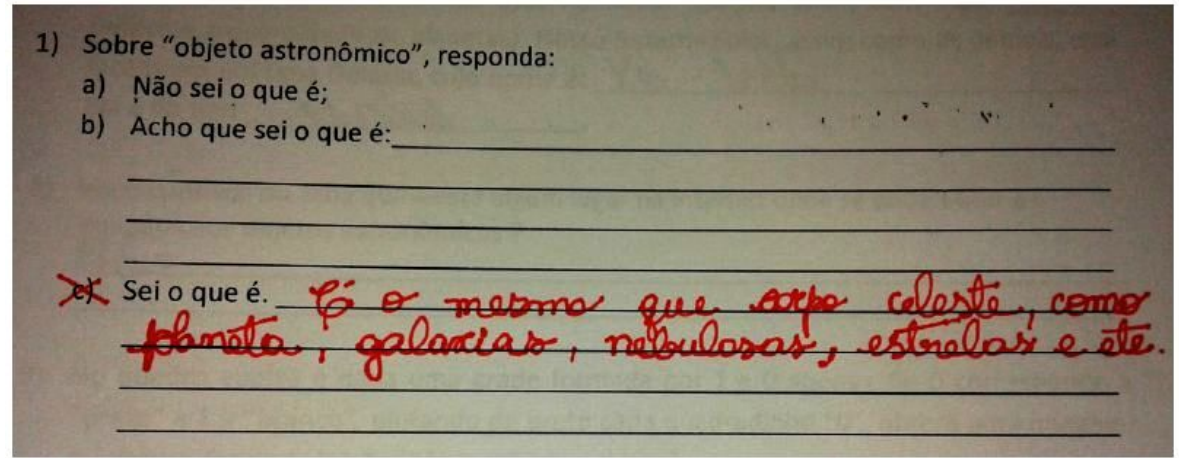

Question 2 (see Table 5, which provides the question and the answer choices) received two wrong answers and 14 correct answers. This finding shows an improvement over the pre-test result, in both percentage and qualitative terms: no student left the question unanswered, and none chose letter $c$, which is the least likely of the choices.

Table 5. Analysis of post-test answers to question 2: "Astronomical objects... "

\begin{tabular}{l|c}
\multicolumn{1}{c|}{ Answer } & QUESTION 2 \\
\hline \multicolumn{1}{c|}{ a) They have different colors; } & 14 \\
\hline b) They have no colors & 0 \\
\hline c) They are "black and white" & 0 \\
\hline Left blank & 2 \\
\hline Total & 16 \\
\hline
\end{tabular}

Only two students gave incorrect answers to question 3 (Figure 5 and Table 6). Nonetheless, this outcome was lower than expected, given that it was expected that $100 \%$ of students would answer correctly. It is important to stress that this reflects the researcher's and teacher's feelings, but as a learning result, it was very satisfactory.

Question 4 (see the Figure 24), received 14 correct answers. This result shows that the students improved from two correct answers to 14 correct answers. It also demonstrates that the element of fun and a process that promotes meaningful content learning can be an effective combination in teaching astronomy to elementary school students. Figures 24 and 25 illustrate two of the 16 answers given. 
Table 6. Analysis of post-test answers to question 3: "All astronomical objects..."

a) Are the same size

b) Vary in size Answer

c) Are almost the same size, with little variation

Left blank

Total

QUESTION 3

Total

Graph 7. Percentage results for question 3 (Table 6)

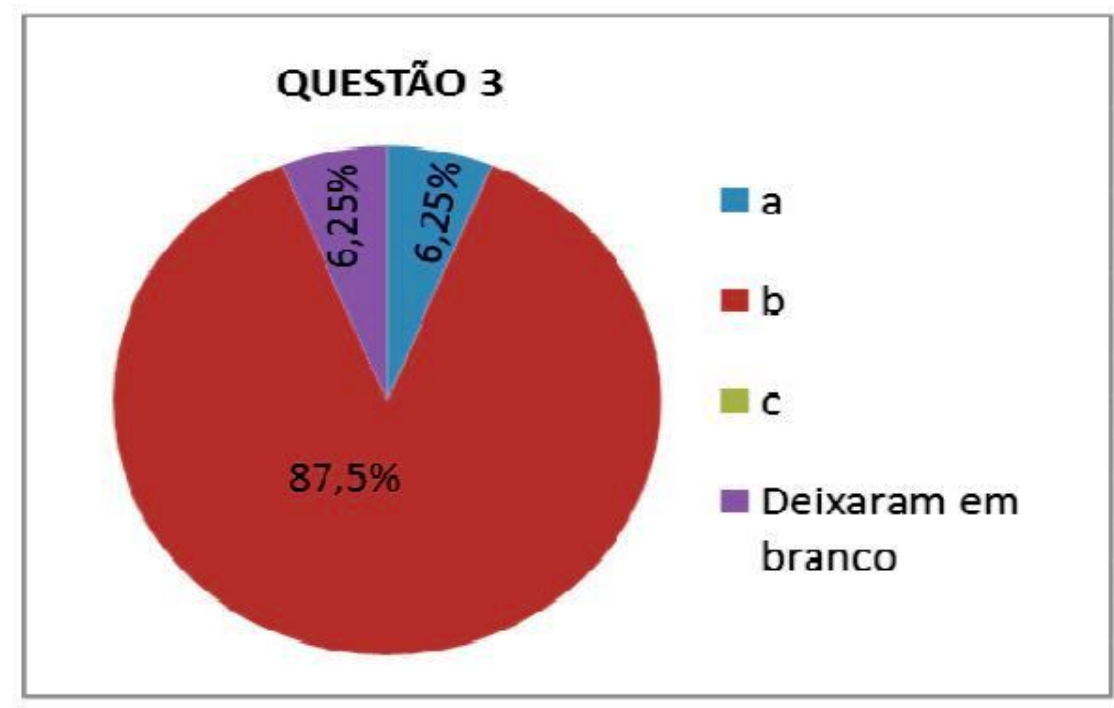

Figure 24. One of the 14 correct answers (Printed text: provided above; Handwritten text: Planets, stars and natural satellites like the moon).

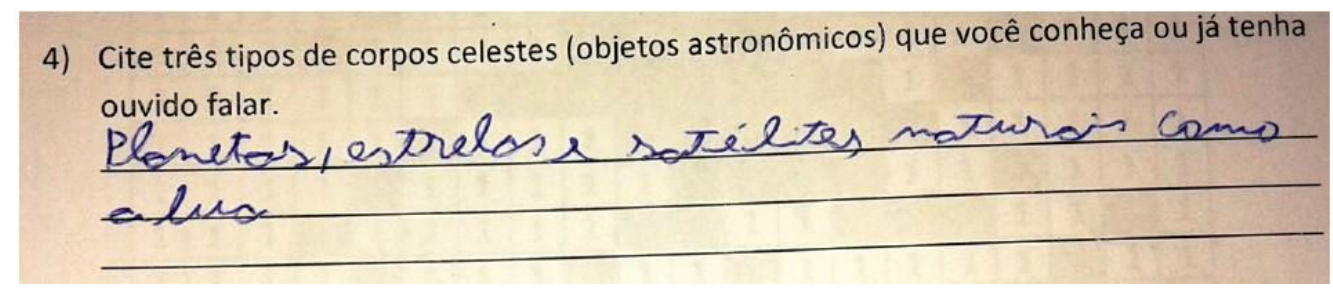

Figure 25. A student's correct answer to this question (Printed text: provided above; Handwritten text: Galaxy, planet, star).

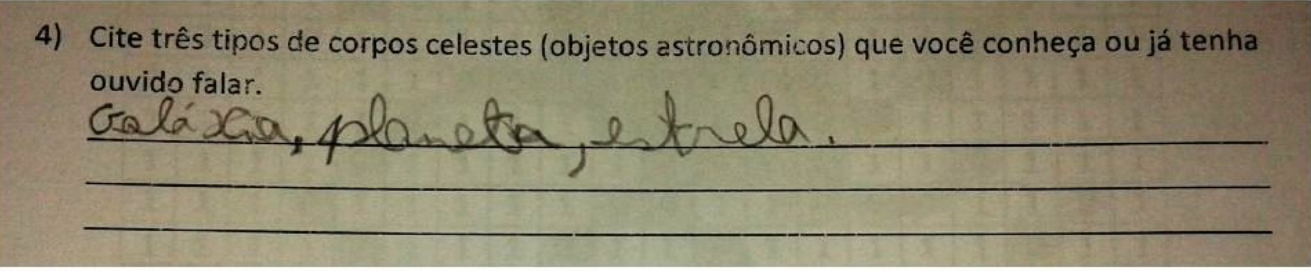

Of the 16 responses to question 5 analyzed, 14 were considered correct (image of a galaxy), representing $87.5 \%$ of the students. Figure 26 illustrates what the teacher called $a$ mandala of answer a, in celebration of the result. This shows that the students learned to classify astronomical objects, at least those that they had encountered. Moreover, 
the audio recording of this activity registers several students stating that they are now able to identify many celestial objects that were previously unknown to them. The audio recording was collected without any prompting of the students by the researcher or teacher.

Figure 26. Analysis of the answers to Question 5, on which 12 of the 16 students chose letter $a$

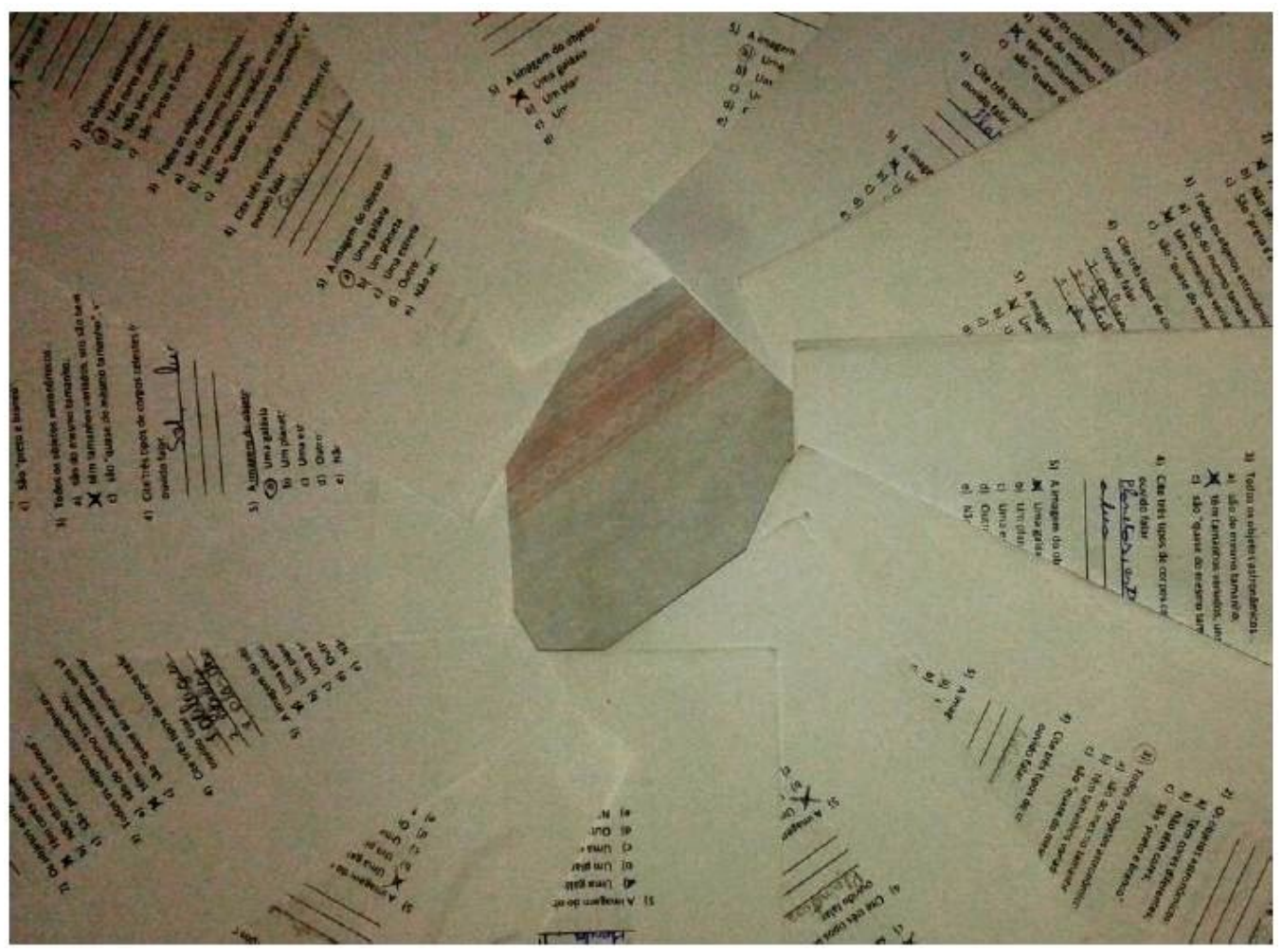

If the student claimed to know some type of astronomical (celestial) object in the answer to question 4 , then the student was asked to provide details in the answer to Question 6. In contrast to the $12.5 \%$ of correct answers on the pre-test, there were 13 correct answers $(81.25 \%)$ to this question on the post-test, indicating improvement in the quality of the answers. Figures 27 and 28 show two students' answers.

Figure 27. Satisfactory answer to question 6 (Printed text: provided above; Handwritten text: A galaxy is home to millions of stars and various planets).

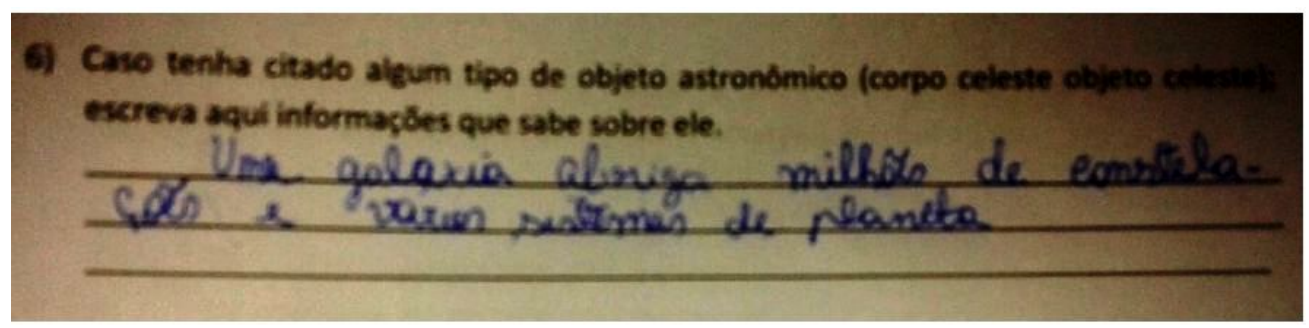


Figure 28. Correct answer to question 6 (Printed text: Write the information you know about the astronomical objects quoted. Handwritten text: Our galaxy is the Milky Way. Our planet and the Earth. The stars have their own light.).

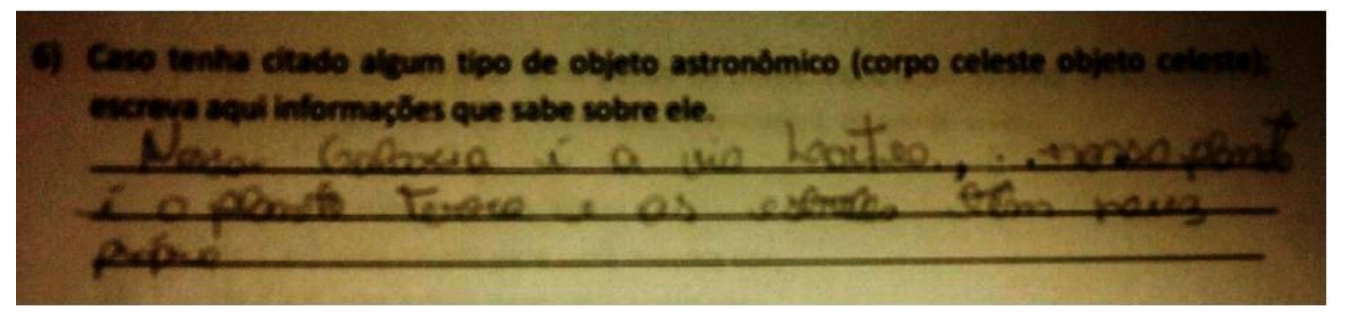

On the pre-test, no student provided a complete answer to question 7; on the post-test, the students generally lived up to expectations (Figure 29), in that 12 answers were completely correct and four were partially correct. No answer was completely wrong.

Question 8 still elicited some unsatisfactory answers, but $56.25 \%$ of the students noted Aladin as a program through which these images can be found. Some answers such as "on the NASA website" or "Google" also appeared less frequently. Although various images of astronomical objects can, in fact, be found on the NASA website and through Google, it was hoped that students' answers would refer to the software program that was discussed in class. The fact that some students noted Aladin (Figure 30), a program with which they had previously been entirely unfamiliar, was considered significant progress as well as successful dissemination of knowledge about the program.

Although Aladin is extensively used by professional astronomers, it is also applicable to teaching astronomical concepts, whether at the elementary, high school, or college level. 
Figure 29. One of the 12 entirely correct answers to question 7

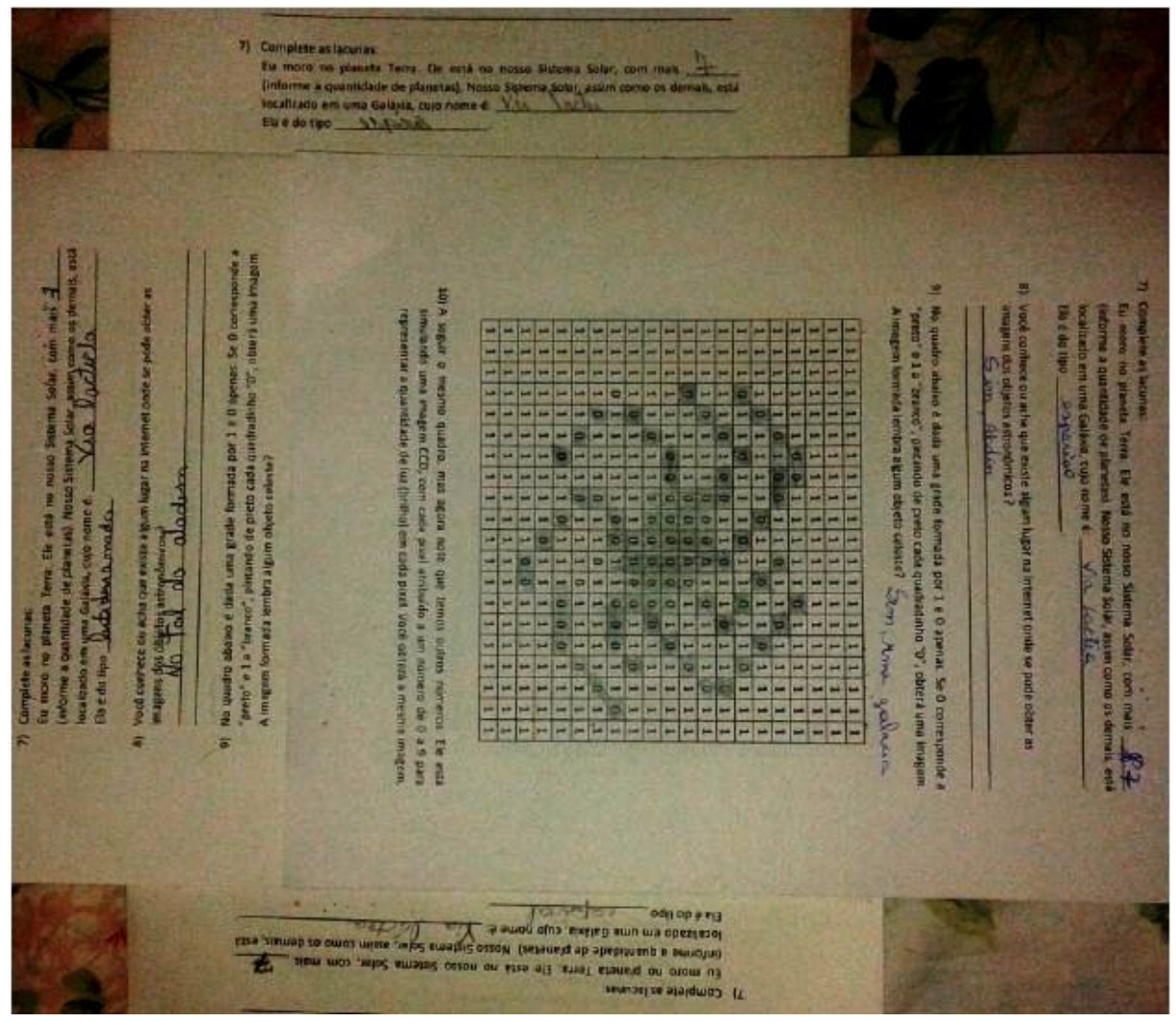

Figure 30. A student's answer to question 8, citing Aladin (Do you know or think that there is any place on the internet where you can get the images of astronomical objects?).

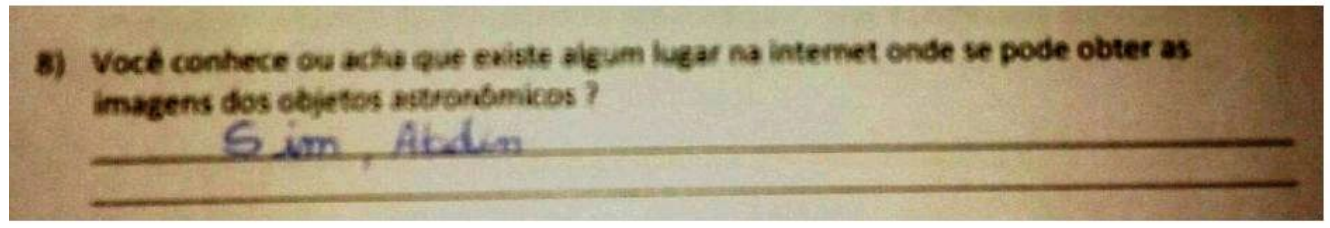

On question 9, only one student had correctly identified the image produced by filling in the "zero" squares as representing a galaxy on the pre-test. In contrast, nine students correctly identified the image as a galaxy on the posttest (Figure 31); of these, five further identified the morphological type as a spiral galaxy. 
Figure 31. A student's answer to question 9, noting that the drawing obtained represents a galaxy (The table below is formed by 1 and 0 only. " 0 " is black and " 1 " is white. Paint each square " 0 " in black, getting an image. Does the formed image remind some celestial object?).

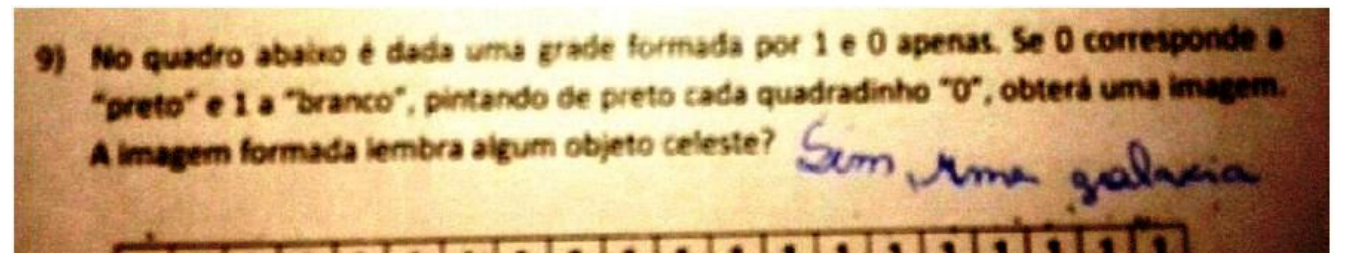

Figure 32. Six students' answers to question 10, noting that the resulting image represents a galaxy
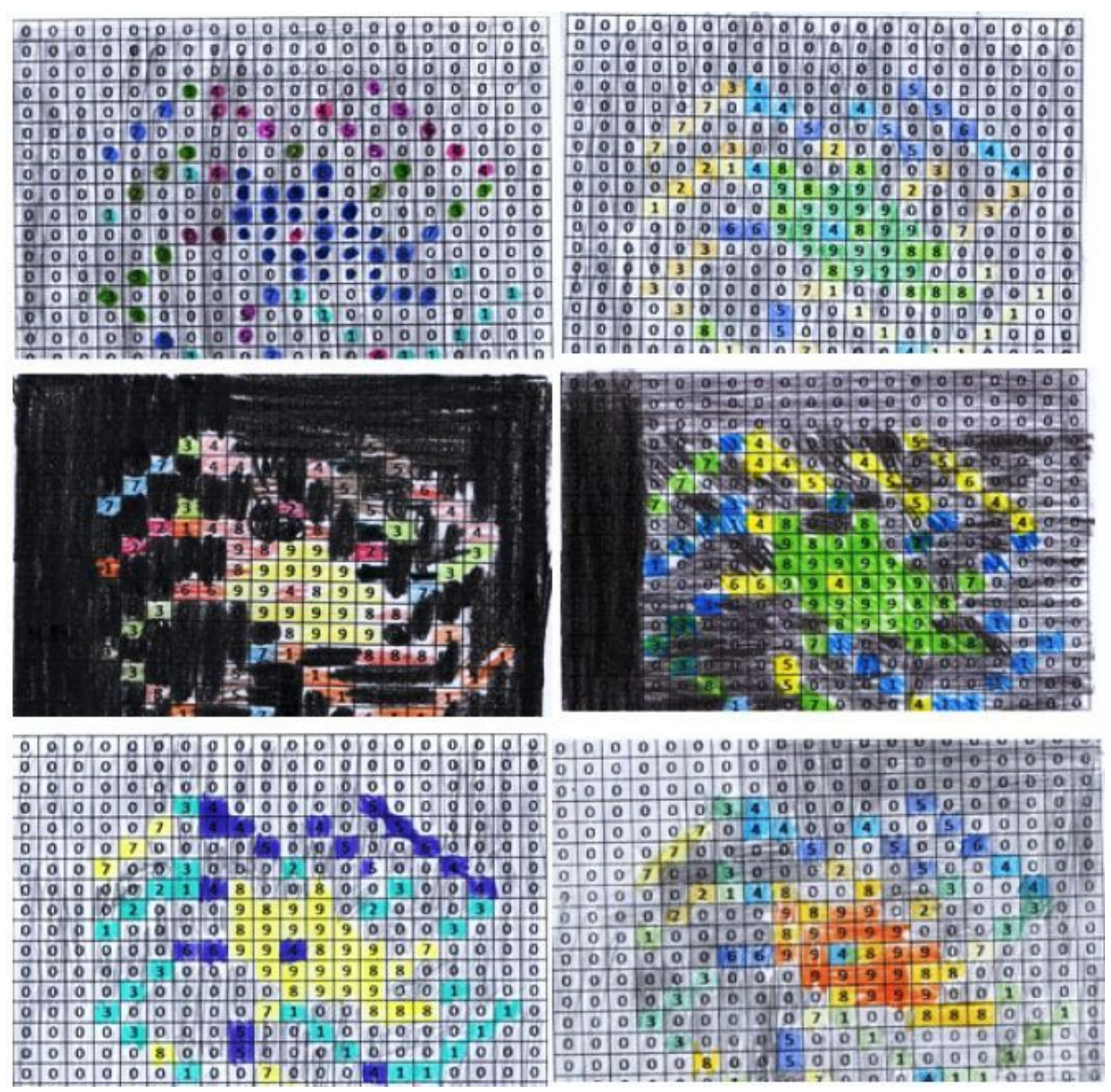

Two students left question 10 blank, whereas the others colored it correctly (Figure 32). Approximately 90\% of these answered that the object that they colored represented a galaxy.

\section{CONCLUSIONS}

In the comparison between the pre-test and the final questionnaire (Table 7), the growth in the cognitive development of apprentices is noticeable and can be observed in the analysis of the normalized gain, that is, considering the gains of the pre-test and which, in percentages, the post-tests have in gain on the previous one, what 
evidences a better cognitive performance referring to the contents approached The students' statements demonstrated that not only did they show meaningful learning, but they also liked the methodology, the applied playfulness and the conduct of the process.

Table 7. Comparison between correct answers on the assessments before (pre-test) and after (post-test) implementation of the learning activity and lesson

\begin{tabular}{c|c|c|c}
\hline Question & Pre-test (\%) & Post-test (\%) & Normalized gain (\%) \\
\hline 1 & 50.00 & 81.25 & 162.5 \\
\hline 2 & 28.60 & 75.00 & 262.2 \\
\hline 3 & 37.50 & 87.50 & 233.3 \\
\hline 4 & 12.50 & 87.50 & 700.0 \\
\hline 5 & 37.50 & 87.50 & 233.3 \\
\hline 6 & 12.50 & 81.25 & 650.0 \\
\hline 7 & 0.00 & 75.00 & 700.0 \\
\hline 8 & 6.25 & 56.25 & 900.0 \\
\hline 10 & 6.25 & 56.25 & 900.0 \\
\hline
\end{tabular}

The methodology can be even more effective, in cognitive terms, if it is incorporated into a program of consistently applying and addressing astronomical concepts (Langhi, 1997). Because this activity was implemented at the elementary school level, we must consider not only the possibility that the students may not have had the assumptions (Moreira, 1999) necessary to anchor the meanings (as, in fact, was made clear by the pre-test results) but also that a more coherent and proper approach would have been for the research project to have been conducted on a broader level so that the "sedimentation" of new concepts might yield higher-quality learning results (Ausubel, 2003). However, even with all of its shortcomings, the study shows that it is possible and even advisable that astronomical concepts be taught beginning in elementary school.

We observed that our study was theoretically grounded in the theory of meaningful learning recommended by David Ausubel (2003) and followed stages of meaning construction by the learner, with the Aladin program underlying the entire process, supporting students' understanding of the concepts taught in the theoretical lessons through images and slides, researcher interventions, and the collective construction of knowledge with the learners.

The Aladin can be used in schools, as it is a free software and now also in Portuguese (Brazilian Portuguese), having been translated specifically for this and other activities that have been part of a wider research of its application from elementary school to teacher training. We hope that these activities, as well as those described in the references of the sites, according to Amôres (2005), Longhini and Menezes (2015), Amantes (2005), Amôres (2012), Oliveira (2015) and Hetem (2015), as well as others not noted, with the objective of being explored by teachers and students of primary, secondary and higher education.

We report the success of the methodology based on the results analyzed and presented, and we suggest teachers adapt these and create their own strategies and methods, taking advantage of the opportunity to learn more not only about astronomical objects but also about other astronomical concepts that can be understood even at the primary grade levels.

Finally, it is also worth noting that this proposal of learning astronomy concepts with the use of specific software does not require that the Professor changes his methodology or his teaching heuristic, since, there is no previous procedure that changes his way of acting or their personal practices already practiced in the classroom. This scenario is salutary in the sense that it does not demand specific training for this besides not providing negative reactive aspects on the part of the Teachers.

We hope that astronomy becomes part of the curriculum, not merely as a unit inserted into other required subjects but as specific content to be taught in elementary school, beginning in the earliest grades. In addition to being of 
interest to students, astronomy is of extreme current relevance and will continue to appear frequently in news reports, debates, websites, and other media that cover this topic.

\section{ACKNOWLEDGMENTS}

We thank SENAI CIMATEC for the encouragement and support of funding.

\section{AUTHOR BIOGRAPHIES}

Melina Silva de Lima is a University Professor in Brazil and holds the degrees of Bachelor in Mathematics with Emphasis in Computer Science, Specialist in Educational projects and Informatics, Specialist in Psychopedagogy, Master in Mathematics Education, Master in Astronomy and is currently a PhD student in Computational Modeling. Email: melinasl_mel@hotmail.com (corresponding author)

Eduardo Brescansin de Amôres holds an Bachelor's Degree in Physics as well as a Masters and aPhD in Astronomy. He has served as a post-doctoral scholar at the Universitat de Barcelona and Institut d'Estudes Espacials de Catalunya, the Observatoire Astronomique de Strasbourg, the National Observatory and is currently a Titular Professor of the Physics Department of the Feira de Santana State University in Brazil.

José Vicente Cardoso Santos holds degrees in physics and education as well as a Masters in International Business and Administration. He has done post-graduate work in Solid State Physics, in Internal Audit, and in Psychopedagogy. Currently, he is a Professor at State University of Bahia in the Department of Exact and Earth Sciences and at SENAI / CIMATEC.

Vera Aparecida Fernandes Martin holds a Masters in Physics (1991) and a Doctorate (1998) in Astronomy. She is a Professor at the Feira de Santana State University and the coordinator of the Professional Master's Degree program in Astronomy at the Bahia State University.

\section{REFERENCES}

Allal, L. Cardinet, J. \& Perrenoud, P. (1986) À Avaliação Formativa Num Ensino Diferenciado. Coimbra: Almedina Bookstore. Amantes, A. (2005). O Entendimento De Estudantes Do Ensino Médio Sobre Movimento Relativo E Referencial Inercial. Master's dissertation, UFMG.

Amôres, E. B. D. (2005). Medição De Brilho Das Estrelas - Técnicas Fotométricas. São Paulo, Iag-Usp. Available from: http://www.Telescopiosnaescola.Pro.R/. Access in: $20 \mathrm{fev} 2018$.

Amôres, E. B. D. (2012). Medição De de Brilho Das das Estrelas - Técnicas Fotométricas. São Paulo, Iag-Usp. Access: http://www.telescopiosnaescola.pro.r/

Ausubel, D. P. (2003). Aquisição E e Retenção De de Conhecimentos: Uma uma Perspectiva Cognitiva. Lisboa: Plátano Publisher.

Bell, T. Wintten, I. H., Fellows, M. (2015). An Enrichment and Extension Programme For Primary-Aged Students. Nova Zelândia: University of Canterbury. Avaible at: http://csunplugged.org/books/

Brasil. Ministério Da Educação. Secretaria De Educação Fundamental. Parâmetros Curriculares Nacionais (1997). Matemática (1st and 2nd Cycles of Elementary Education). V. 3. Brasília: MEC.

Busselle, M. (1998). Tudo Sobre Fotografia. São Paulo: Livraria Pioneira.

Filho, K. de S. O., Saraiva, M. de F. O. (2014). Astronomia e Astrofisica. Rio Grande so Sul: Depto de Astronomia da UFRGS.

Hetem, A. (1996). Estudo Da da Estrutura De de Nuvens Moleculares. São Paulo: Universidade De São Paulo - UspUSP, Doctoral thesis.

Hetem, J. G. (2015). Uma Estrela-Bebê De 10 Mil Anos. Available from: http://www.telescopiosnaescola.pro.br/gregoriotexto.pdf. Access in: 21, 24 June 2015.

Inep. Prova Brasil e Saeb. Brasília, DF. (2011). Available from www.portal.inep.gov.br. Access in 12/05/2018.

Lacanallo, L. F. (2011). O Jogo No no Ensino Da da Matemática: Contribuições Para para O o Desenvolvimento Do do Pensamento Teórico. Paraná: Universidade Estadual De Maringá, Doctoral thesis.

Langhi, R. (1997). Ideias De de Senso Comum Em Astronomia. Laboratórios Virtuais. Caderno Catarinense de Ensino de Física. 
Vol 14, № 3, 1997. Avaible at Http://Telescopiosnaescola.Pro.Br/Langhi.Pdfi.

Langhi, R., \& Nardi, R. (2007). Ensino De de Astronomia: Erros erros Conceituais Mais mais Comuns Presentes Em em Livros Didáticos De de Ciências. Revista Brasileira De Ensino De Física. 24, N. 1. P.87-111, Abr. 2007.

Longhini, M.D., Menezes, L. D. de Deus. (2015). (Objeto Virtual de Aprendizagem No Ensino De Astronomia: Algumas Situações Problemas Propostas A Partir Do Software Stellarium. Available from: https://periodicos.ufsc.br/index.php/fisica/article/view/2175-7941.2010v27n3p433. Access in: 25 June 2015.

Moreira, M. A. (1999). Teorias De de Aprendizagem. São Paulo: Epu.

Oliveira, M. K. (2015). Jovens e adultos como sujeitos de conhecimento e aprendizagem. XXII Reunião Anual de ANPED. Caxambu, MG.

Rabelo, E. H. (2009). Avaliação: Novos Tempos, Novas Práticas. $8^{\mathrm{a}}$ Ed. Petrópolis, Rj: Vozes.

Uchoa, A. R. (2003). Organizador Prévio Virtual Para O o Ensino De de Física. Universidade Federal Do Ceará. Master's dissertation. Ceará. 